\begin{tabular}{|c|l|}
\hline Title & The influence of the Gulf Stream on wintertime European blocking \\
\hline Author(s) & O'Reilly, Christopher H.; Minobe, Shoshiro; Kuwano-Y oshida, A kira \\
\hline Citation & $\begin{array}{l}\text { Climate Dynamics, 47(5), 1545-1567 } \\
\text { https://doi.org/10.1007/300382-015-2919-0 }\end{array}$ \\
\hline Issue Date & 2016-09 \\
\hline Doc URL & http://hdl.handle.net/2115/67107 \\
\hline Rights & The final publication is available at link.springer.com \\
\hline Type & article (author version) \\
\hline File Information & GulfStreamBlocking_REV2_FINAL.pdf \\
\hline
\end{tabular}

Instructions for use 


\section{The influence of the Gulf Stream on wintertime European blocking}

Christopher H. O'Reilly ${ }^{1^{*}}$, Shoshiro Minobe ${ }^{1}$ and Akira Kuwano-Yoshida ${ }^{2}$

${ }^{1}$ Department of Natural History Sciences, Graduate School of Science, Hokkaido University, Sapporo, Japan.

${ }^{2}$ Application Laboratory, Japan Agency for Marine-Earth Science and Technology, Yokohama, Kanagawa, Japan.

${ }^{*}$ Corresponding author address: Christopher H. O’Reilly, Department of Physics, Atmospheric, Oceanic and Planetary Physics, Parks Rd, Oxford OX1 3PU, UK

E-mail: christopher.oreilly@physics.ox.ac.uk 


\section{Abstract}

Wintertime blocking is responsible for extended periods of anomalously cold and dry weather over Europe. In this study, the influence of the Gulf Stream sea surface temperature (SST) front on wintertime European blocking is investigated using a reanalysis dataset and a pair of atmospheric general circulation model (AGCM) simulations. The AGCM is forced with realistic and smoothed Gulf Stream SST, and blocking frequency over Europe is found to depend crucially on the Gulf Stream SST front. In the absence of the sharp SST gradient European blocking is significantly reduced and occurs further downstream. The Gulf Stream is found to significantly influence the surface temperature anomalies during blocking periods and the occurrence of associated cold spells. In particular the cold spell peak, located in central Europe, disappears in the absence of the Gulf Stream SST front. The nature of the Gulf Stream influence on European blocking development is then investigated using composite analysis. The presence of the Gulf Stream SST front is important in capturing the observed quasi-stationary development of European blocking. The development is characterised by increased lowertropospheric meridional eddy heat transport in the Gulf Stream region and increased eddy kinetic energy at upper-levels, which acts to reinforce the quasi-stationary jet. When the Gulf Stream SST is smoothed the storm track activity is weaker, the development is less consistent and European blocking occurs less frequently. 


\section{Introduction}

Atmospheric blocking typically refers to phenomena during which the normal eastward migration of cyclones is blocked by a larger-scale high, with easterly winds replacing the prevailing westerlies, often lasting a week or more. Wintertime midlatitude blocking frequency in the Northern Hemisphere peaks in two regions, one over the eastern North Pacific and a larger maximum over Europe (Tibaldi and Molteni 1990), where blocking anomalies act to obstruct the migratory weather systems that transport warm, moist maritime air to Europe and are responsible for its relatively mild winters (Seager et al. 2002). Over Europe in particular, blocking anomalies are responsible for extremely cold and dry weather conditions (Rex 1951; Trigo et al. 2004; Sillmann et al. 2011) along with extended cold spells, which pose serious hazards to society (Rex 1950; Huynen et al. 2001; Buehler et al. 2011).

Since being first documented in the 1940s (Namias 1947; Berggren et al. 1949) the general dynamical features of midlatitude blocking events have become well established. A warm, low potential vorticity (PV), large-scale air mass of subtropical origin becomes cutoff further poleward, in an extratropical region of higher ambient PV (Hoskins et al. 1985; Hoskins 1997) and this type of irreversible Rossby wavebreaking has been shown to be closely connected to the initiation of blocking highs in the midlatitudes (Pelly and Hoskins 2003; Tyrlis and Hoskins 2008a). The air mass develops anomalous anticyclonic circulation with easterly winds on its southern flank. This influences the upstream weather systems such that they preferentially reinforce the low PV anomaly and act to maintain the blocking (e.g. Illari and Marshall 1983; Shutts 1986), through the straining of upstream eddies by the blocking anomaly (Shutts et al. 1983) or selective absorption (Yamazaki and Itoh 2013a; Yamazaki and Itoh 2013b); indeed both mechanisms may be important (Luo et al. 2014).

Blocking events over Europe and the North Pacific, however, display quite different characteristics. Blocking anticyclones over Europe tend to be accompanied by a cyclone on the 
equatorward side, exhibiting a meridional dipole-type structure (e.g. Rex 1950), whereas North Pacific anticyclones tend to be flanked by two troughs, resembling an "omega" structure. A particularly curious feature of European blocking is the lower frequency (in comparison to synoptic eddies) upstream planetary wave pattern that emerges across the Atlantic over a few days leading up to blocking events (H. Nakamura 1994; Michelangeli and Vautard 1998). The wave train becomes almost stationary as the ridge amplifies (Altenhoff et al. 2008) and ultimately breaks, with a low PV anomaly becoming cut off over Europe. Masato et al. (2012) showed that cyclonic upper-level wave breaking primarily initiates blocking episodes over all regions except for Europe (and to a lesser extent Asia), where the onset of blocking is predominantly through anticyclonic wave breaking (as was also demonstrated by Davini et al. (2012) using a two-dimensional diagnostic). The anticyclonic overturning of large-scale waves during European blocking onset was also observed by a composite analysis of blocking events (Nakamura et al. 1997). The presence of intense extratropical cyclogenesis upstream has been observed during the development of both European (Colucci 1985; Crum and Stevens 1988; Michel et al. 2012) and Pacific blocking (Colucci and Alberta 1996; Nakamura and Wallace 1990; Nakamura and Wallace, 1993). However, Nakamura et al. (1997) demonstrated that advection by the low-frequency wind component was sufficient to simulate European blocking development (as was also emphasised in the idealised study of Swanson (2001)), whereas the forcing by transient eddies was found to be of primary importance in generating North Pacific blocking events.

Despite recent improvements, atmospheric blocking continues to be a problem in climate models. The largest blocking biases in the CMIP3 and CMIP5 model generations occur over Europe, where blocking frequency is grossly underestimated (e.g. Scaife et al., 2010; Masato et al., 2013), regardless of which blocking index is used (Doblas-Reyes et al. 2002; Barnes et al. 2011). The underestimation has been linked to biases in the mean model climatologies (Scaife et 
al. 2011) and the associated overly strong westerlies that act to inhibit blocking formation (e.g. Barriopedro et al. 2010). Since higher-resolution models can resolve blocking reasonably well (Jung et al. 2012), the inability of climate models to effectively capture blocking has also been attributed to insufficient resolution (Matsueda et al., 2009; Anstey et al., 2013) and the inability to effectively simulate transient eddies (Berckmans et al. 2013).

Evidence has recently emerged suggesting that North Atlantic sea surface temperatures influence wintertime blocking frequency over Europe. Scaife et al. (2011) found that correcting the sea surface temperature (SST) bias over the North Atlantic (a feature common amongst climate models) in the HadGEM3 model reduced the zonal wind bias and resulted in a significantly improved simulation of wintertime European blocking. Although this highlights the apparent importance of the North Atlantic SST distribution, the mechanisms through which the SST influences European blocking remain unclear.

The North Atlantic most strongly affects the overlying atmosphere in the Gulf Stream region, where narrow bands of intense evaporation and precipitation are observed along the strong SST front (Minobe et al., 2008; Minobe et al., 2010). Sharp SST gradients have been shown to significantly influence the position and/or intensity of storm tracks using various idealized models (Brayshaw et al. 2008, 2011; Nakamura et al. 2008; Sampe et al. 2010; Deremble et al. 2012; Ogawa et al. 2012) and in a more realistic regional model of the North Atlantic (Woollings et al. 2009). Kuwano-Yoshida et al. (2010) used an atmospheric general circulation model (AGCM) with realistic and smoothed Gulf Stream SST gradients to demonstrate the importance of the SST front on the narrow Gulf Stream rain band. The sensitivity of the Gulf Stream rain band to the SST gradient was further emphasised by the study of Brachet et al. (2012). Using AGCM experiments, Hand et al. (2013) found that Gulf Stream SST variability can substantially influence local precipitation. Small et al. (2013) used an AGCM, with similar SST profiles to Kuwano-Yoshida et al (2010), to investigate the storm track response to the Gulf 
Stream SST front and found that it exhibits a significant influence on the storm track, particularly over the western Atlantic. In spite of the evidence of the Gulf Stream influence on the North Atlantic storm track, the potential influence of the Gulf Stream on European blocking has not previously been addressed.

The Gulf Stream has previously been shown to have a significant influence over a wide range of timescales. Recent studies have shown that the Gulf Stream is related to local diurnal cycles in precipitation (Minobe and Takebayashi 2014) and lightning (Virts et al. 2015). The Gulf Stream influences the development of extratropical cyclones, on timescales of a few days (e.g. Cione et al 1993, Booth et al. 2012). Interannual SST variability has been shown to account for most of the precipitation variability in the Gulf Stream region (Hand et al. 2014) and the Gulf Stream also anchors a strong time mean precipitation band along its southern flank (e.g. Minobe et al. 2008; Minobe et al. 2010; Kuwano-Yoshida et al. 2010). Here we investigate the influence of the Gulf Stream SST front on wintertime European blocking and show that the Gulf Stream also has a significant influence on timescales on the order of a week or more, significantly influencing the subseasonal variability of European winters.

In this paper we analyse a reanalysis dataset, along with a pair of AGCM simulations (both with and without realistic Gulf Stream SST boundary conditions) to examine the influence of the Gulf Stream on European blocking. The data, model simulations and methods are described in more detail in section 2 . In section 3 we use an objective binary index of midlatitude blocking to assess the influence of the Gulf Stream SST distribution on blocking frequency over Europe. The SST profile is found to significantly influence both the blocking frequency and the occurrence of associated cold spells. Using a composite approach, we then examine the role of the Gulf Stream during the evolution (with particular focus on the development phase) of European blocking in section 4. The Gulf Stream SST is found to play an 
important role in the unique quasi-stationary nature of European blocking generation. Further discussion of our results and some concluding remarks follow in section 5 .

\section{Model simulations, data and methodology}

2.1 Model simulations and data

In this study we analyse the results of two contrasting 20-year AGCM simulations that were performed using the "AGCM for Earth Simulator (version 3)" (AFES) model developed and run at the Japan Agency for Marine-Earth Science and Technology (Ohfuchi et al. 2004; Enomoto et al. 2008; Kuwano-Yoshida et al. 2010b). The model setup is similar to that used by Minobe et al. (2008) and Kuwano-Yoshida et al. (2010), who analysed a 5-year intergration of the previous version of the AFES model. The version of the AGCM used in this study has previously been used to analyse explosively deepening extratropical cyclones in ensemble forecasts (Kuwano-Yoshida and Enomoto; Kuwano-Yoshida 2014). The model has a horizontal resolution of T239 $(\sim 50 \mathrm{~km})$ and 48 sigma levels in the vertical. The model employs the Emanuel convection scheme (e.g. Emanuel and Zivkovic-Rothman 1999). We analyse the AFES output on a $0.5^{\circ}$ horizontal grid at 6-hourly interval.

For the lower boundary condition the NOAA Optimally Interpolated (AVHRR-only) $0.25^{\circ}$ Daily SST (Reynolds et al. 2007) is used from September 1981 to August 2001. The control simulation was performed using the SST boundary condition as provided in the dataset (hereafter referred to as CONTROL); the second simulation used the SST data smoothed over the Gulf Stream region by applying a 1-2-1 running mean filter in both the zonal and meridional directions 200 times on the $0.25^{\circ}$ grid in the region $85^{\circ}-30^{\circ} \mathrm{W}, 25^{\circ}-50^{\circ} \mathrm{N}$ (hereafter referred to as SMOOTH). The climatologies of the CONTROL and SMOOTH SST profiles, for the boreal winter period used in this study (over the months of December, January and February), are shown in Figure 1. The 20-year simulations are shorter than other studies on 
midlatitude circulation responses to SST. However, the SST smoothing that is used in the SMOOTH simulation is significantly larger than, for example, interannual SST variability, and generates significant differences between the CONTROL and SMOOTH simulations. Results of these two simulations are closely compared with the 31 years of the NCEP Climate System Forecast Reanalysis (hereafter NCEP-CFSR) dataset from 1979 to 2009, which is available on a $0.5^{\circ}$ grid at 6-hourly intervals (Saha et al., 2010).

\subsection{Midlatitude blocking index}

To identify blocking events we calculated a binary blocking index following Masato et al. (2013). The index identifies reversals of the midlatitude geopotential height gradient at $500 \mathrm{hPa}$ (hereafter Z500) and is computed as follows. The daily mean Z500 fields are first interpolated onto a $5^{\circ}$ grid in the longitudinal direction (since we are only interested in robust, large-scale blocking features). At each longitudinal grid point the following meridional integrals are then computed:

$$
\bar{Z}^{N}=\frac{2}{\Delta \varphi} \int_{\varphi_{0}}^{\varphi_{0}+\Delta \varphi / 2} Z_{i} d \varphi ; \quad \bar{Z}^{S}=\frac{2}{\Delta \varphi} \int_{\varphi_{0}-\Delta \varphi / 2}^{\varphi_{0}} Z_{i} d \varphi .
$$

Here $\Delta \varphi=30^{\circ}$ defines the meridional extent of the two sectors and $\varphi_{0}$ is the central blocking latitude as explained below. The blocking index $B$ is defined as $B=\bar{Z}^{N}-\bar{Z}^{S}$, such that positive $B$ indicates a large-scale reversal of the meridional geopotential height gradient.

The central blocking latitude $\varphi_{0}$ is a function of longitude and is set to the latitude of the maximum in the mean (DJF) transient kinetic energy at 500hPa (similar to Pelly and Hoskins (2003) and Barnes et al. (2012)). The synoptic transient eddy velocity components were calculated using a 2-8 day band pass Lanczos filter (Duchon et al. 1979). This ensures that the blocking index, $B$, effectively identifies large-scale anomalies that obstruct the typical migration of midlatitude weather systems. The central blocking latitudes calculated for NCEP-CFSR, 
CONTROL and SMOOTH are closely located, within $4^{\circ}$ in latitude, of one another at all longitudes in the Euro-Atlantic sector.

The blocking index $B$ is computed at the central blocking latitude and at latitudes $4^{\circ}$ to the north and south, and the maximum value of $B$ is retained. The calculation is performed for each day such that positive $B$ represents instantaneous local blocking at each longitude. A check is then carried out to eliminate the blocking structures that span less than $15^{\circ}$ in longitude. A further check is then performed to ensure that the blocking anomalies remain approximately stationary, within a given sector of $65^{\circ}$ longitude about a central longitude (following, e.g., Pelly and Hoskins (2003); Masato et al. (2012)) for at least 5 days, consistent with observed persistence (Masato et al. 2009), which avoids the detection of slow moving ridges. The remaining longitudes with positive $B$ are then considered "blocked". Since the blocking index $B$ represents blocking or non-blocking conditions it is referred to as the binary index throughout this study.

\subsection{Transient eddy forcing}

To assess the eddy forcing of the large-scale flow in section 4 we will analyse composites of $\mathbf{E} \cdot \mathbf{D}$ (at $300 \mathrm{hPa}$ ), which is a measure of the kinetic energy exchange between the synoptic eddies and the large-scale flow (Mak and Cai 1989). This diagnostic has previously been used to assess the action of the eddies on the North Atlantic jet (e.g. Cai et al. 2007; Raible et al. 2010; Lee et al. 2011; Woollings et al. 2014). Here E is the horizontal part of the local Eliassen-Palm flux vector of Trenberth (1986):

$$
\mathbf{E}=\left(\left(v^{\prime 2}-u^{\prime 2}\right) / 2,-u^{\prime} v^{\prime}\right)
$$

where the eddy variables are 2-8 day band-pass filtered, as before. The vector $\mathbf{D}$ represents the deformation field of the large-scale or background flow and is defined as 


$$
\mathbf{D}=\left(\frac{\partial \bar{u}}{\partial x}-\frac{\partial \bar{v}}{\partial y}, \frac{\partial \bar{v}}{\partial x}+\frac{\partial \bar{u}}{\partial y}\right),
$$

where the overbar denotes an 8-day low-pass filtered velocity, used to define the background flow for each composite separately. The time period used to define the background flow is shorter than in previous studies but here we aim to assess the action of the eddies on the quasistationary flow, which is well captured in the 8-day low-pass fields.

\subsection{Statistical tests and anomaly calculations}

Statistical significance of the difference plots (CONTROL minus SMOOTH) for entire winter periods in section 3 are calculated using Monte Carlo resampling. The statistics for each winter in CONTROL and SMOOTH are combined and randomly split into two equal sets of 20 winters and the magnitude of the difference is saved. The process is repeated 1000 times to assess the probability that the difference between the datasets could occur at random.

The significance of the composite differences in section 4 is calculated using a similar Monte Carlo resampling. The blocking composites in section 4 are produced from 20 events from each of the AGCM experiments. For each difference map, the individual composite members from CONTROL and SMOOTH are combined and randomly split to produce two equal composites of 20 random members and the magnitude of the difference is saved. The process is repeated 1000 times to assess the probability that the difference between the two composites could occur at random.

Anomalous fields in section 3 are defined at each grid point by removing a seasonal cycle calculated from the first three Fourier harmonics. Since the seasonal cycle for storm track variables (e.g. eddy kinetic energy and meridional eddy heat transport) are less well defined, the anomalous fields for the composite analysis in section 4 are calculated by simply removing the wintertime (i.e. DJF) climatologies. 


\section{Influence on blocking frequency and cold spells}

3.1 Blocking frequency and surface temperature

Figure 2 shows the wintertime (i.e. DJF) climatologies of $Z(500 \mathrm{hPa})$ and $\mathrm{T}(2 \mathrm{~m})$, two pertinent fields that we will be analysed in this section. The climatological $Z(500 \mathrm{hPa})$ fields in the NCEP-CFSR, CONTROL and SMOOTH compare favourably. The difference (defined as CONTROL minus SMOOTH) between the AGCM experiments is fairly modest, with increased midlatitude ridging over Europe and the Eastern Pacific. The $\mathrm{T}(2 \mathrm{~m})$ fields are also all quite similar, with the largest differences over the Gulf Stream, where the SST field is smoothed. There are no large differences in the mean temperature over mainland Europe but CONTROL exhibits slightly warmer mean surface temperatures over Scandanavia and the west coast of North America, consistent with the increase in the mean ridges observed in the $\mathrm{Z}(500 \mathrm{hPa})$ fields. Figure 3 shows the wintertime blocking frequencies calculated from NCEP-CFSR, CONTROL and SMOOTH data. The CONTROL simulation underestimates blocking frequency at all longitudes compared to NCEP-CFSR but the shape of the distribution is well captured, with the peak approximately collocated at about $15^{\circ} \mathrm{E}$. The SMOOTH simulation further underestimates blocking frequency, particularly over Europe, has a flatter distribution and peaks slightly further downstream, with a higher proportion of blocking occurring over Eastern Europe. The largest difference in blocking frequency between the two AGCM simulations occurs upstream of the blocking peaks, close to the Greenwich meridian, where blocking frequency is about 50\% larger in the CONTROL simulation. The simulations exhibit negligible differences in blocking frequency over the eastern North Pacific.

The strong influence of the Gulf Stream SST on the frequency and distribution of European blocking suggests that there might be a significant subsequent influence on European winter temperatures, particularly the anomalously cold temperatures that occur during blocking 
events. The difference in the longitudinal distributions of blocking frequency in the AFES simulations suggests that conditions during European blocking periods might have substantial geographical differences. To evaluate the conditions during European blocking periods in each of the datasets we first define European blocking days to be those on which the blocking index identifies blocking that spans at least $15^{\circ}$ in longitude between $20^{\circ} \mathrm{W}$ and $40^{\circ} \mathrm{E}$. The results presented here were not found to be sensitive to moderate adjustments (e.g. $\left.+/-10^{\circ}\right)$ in the definition of the European blocking region.

Figure 4 maps the composite 2-metre daily-mean air-temperature (i.e. $\mathrm{T}(2 \mathrm{~m})$ ) anomalies, normalised by the standard deviation at each grid point, for each of the datasets. The normalised anomalies (rather than the raw composite anomalies) are plotted to account for the contrast in the standard deviation of surface temperature when comparing continental regions in Eastern Europe with regions in closer proximity to the sea. As found in previous studies (e.g. Trigo et al 2004; Sillmann and Croci-Maspoli 2009; Masato et al 2014), there are cold anomalies across nearly all of Europe, roughly spanning $35^{\circ}-65^{\circ} \mathrm{N}$, in the NCEP-CFSR dataset (Figure 4a). The coldest (normalised) anomaly during blocking days occurs over a large region along the northern coast of continental Europe, from $5^{\circ} \mathrm{W}$ to $30^{\circ} \mathrm{E}$. The normalised cold anomaly in the CONTROL simulation (Figure $4 \mathrm{~b}$ ) is broadly similar to that observed in NCEP-CFSR. Again, the maximum surface cold anomaly occurs along the northern coastline of central Europe but only extends to around $25^{\circ} \mathrm{E}$ and is also stronger than in NCEP-CFSR. This likely reflects the narrower distribution of blocking frequency in the CONTROL simulation.

The cold temperature anomaly during blocking days in the SMOOTH simulation is quite different from those in NCEP-CFSR and CONTROL. The coldest normalised anomaly is weaker than in both NCEP-CFSR and CONTROL. The coldest anomaly in SMOOTH also occurs further south and about $15^{\circ}$ in longitude further downstream, over Ukraine (Figure 4c). The difference between the CONTROL and SMOOTH simulations (defined here and 
throughout as CONTROL minus SMOOTH) is shown, only where both datasets exhibit a cold anomaly, in Figure 4d. The map is characterized by a zonally oriented dipole, reflecting the cold anomalies located over central/western Europe in the CONTROL simulation compared to the SMOOTH simulation, which exhibits coldest temperature anomalies over eastern Europe. This is consistent with the region of peak blocking frequency in the SMOOTH simulation being located further eastward than in both NCEP-CFSR and CONTROL (Figure 3).

The cold surface temperature anomalies during blocking periods are primarily associated with anomalous advection (e.g. Trigo et al. 2004). Figure 5 shows the composite zonal and meridional $10 \mathrm{~m}$ wind anomalies during blocking periods. Note, only regions over land are shown because whilst the wind speeds over the ocean are significantly larger, it is primarily the anomalous advection of cold continental air that generates the extreme cold anomalies during blocking periods (c.f. surface temperature climatologies shown in Figure 2). Easterly wind anomalies occur in essentially all regions that display cold anomalies during blocking periods, peaking in western/central Europe in all three datasets. Similarly anomalous northerly surface winds are observed over the band of Europe that experiences cold conditions as well as further to the north. The NCEP-CFSR and CONTROL maps are very comparable, whereas the northerly wind anomaly in the SMOOTH simulation is centred further to the east, which again might be expected from the distribution of blocking frequency (Figure 3). Analysis of the difference maps (shaded only where both CONTROL and SMOOTH exhibit negative anomalies) reveals that the anomalous northeasterly winds tend to occur further south and east in the SMOOTH simulation. Referring back to the map of temperature anomaly difference (i.e. Figure $4 \mathrm{~d}$ ), it is clear that this temperature difference is in large part due to the anomalous advection during European blocking periods.

\subsection{European cold spells}


In this subsection, we examine the influence of the Gulf Stream on the occurrence of

cold spells over Europe. The significant increase in blocking frequency observed in the CONTROL simulation compared to that in SMOOTH, together with the different geographical distribution of surface temperature anomalies during blocking, indicates that the distribution of extended winter cold spells may be influenced by the Gulf Stream SST profile. Here, we use the World Meteorological Organisation definition of a cold spell as a period in which the daily temperature anomaly is in the bottom tenth percentile of the anomalous temperature distribution (defined separately at each grid point, for each dataset) for more than five consecutive days (see also Klein-Tank et al. (2002)). The results presented below are not qualitatively different with moderate changes (e.g. +/- 1 day) to the duration threshold.

Figure 6 shows the number of cold spell days per winter for each of the datasets. The cold spell days in both NCEP-CFSR and CONTROL occur mainly in a narrow region near to the northern coast of central Europe, similar to the region where the coldest temperature anomalies occur during blocking periods in these two datasets (i.e. Figure 3). As in the surface temperature anomaly distribution, the NCEP-CFSR region of most frequent cold spells extends slightly further into Eastern Europe compared with CONTROL. The SMOOTH simulation on the other hand has a much different distribution of cold spell days, with two weaker maxima occurring over northern France/southern U.K. and over Belarus/Ukraine, respectively. The low number of cold spell days over central Europe is consistent with less frequent blocking compared with the CONTROL simulation. The peak over Eastern Europe in the SMOOTH simulation might have been anticipated from the distribution of temperature anomalies during blocking periods (i.e. Figure 4), which are colder further downstream. Figure $6 \mathrm{~d}$ shows the difference between the CONTROL and SMOOTH simulations and indicates that there are more cold spell days in the CONTROL simulation over northern-central Europe, whereas there are more cold spell days in the SMOOTH simulation over eastern Europe, consistent with the 
difference map of temperature anomalies shown in Figure 4d. Significant differences in the number of cold spell days also occur over the Iberian and Anatolian peninsulas.

To assess the extent to which the cold spell distributions are attributable to the observed European blocking distributions, we have split the European winter periods into blocking (between $20^{\circ} \mathrm{W}$ and $40^{\circ} \mathrm{E}$ as before) and non-blocking periods. Figure 7 shows the number of cold spell days identified in each of these periods for all three datasets. The percentage of the total winter days that contribute to each map is indicated in the top-left corner of each panel. For example, in the NCEP-CFSR dataset European blocking events are present on $28.8 \%$ of the total days, whereas the remaining $71.2 \%$ of the winter days are considered "non-blocking" periods. It is immediately clear that the blocking periods in NCEP-CFSR and CONTROL are responsible for the vast majority of the cold spell days, particularly in the peak region across central Europe. Blocking periods make up much less of the winter period in the SMOOTH simulation, and the cold spells cannot be clearly attributed to blocking. Whilst the cold spell days over Western Europe and Iberia occur mostly in blocking periods, the cold spell days over Eastern Europe happen during both blocking and non-blocking periods.

These results suggest that the Gulf Stream is very important in determining the strong peak in midlatitude wintertime blocking frequency observed over Europe, as well as the associated spells of extremely cold surface temperatures. Analysis of the length of the European blocking events in CONTROL and SMOOTH, not shown, reveals no clear difference in the distribution of period and the increased blocking frequency in the CONTROL simulation is primarily the result of a significantly larger number of blocking events. At this point it is natural to consider what physical processes are determining the influence of the Gulf Stream on European blocking events. This will be investigated in the next section.

\section{Influence on blocking development}


In this section we investigate the role of the Gulf Stream in the development of European blocking events, using composite analysis to try to understand why European blocking is sensitive to the presence of the Gulf Stream SST front.

\subsection{Composite blocking index}

To investigate the source of the difference in blocking between the two simulations, we produced composites of European blocking evolution. Composite analysis emphasises common features and has proven useful in isolating important characteristics of blocking (e.g. Tyrlis and Hoskins 2008b; Altenhoff et al. 2008). Here, we use an additional index to identify the "strongest" blocking highs in the $0^{\circ}-10^{\circ} \mathrm{E}$ longitude band, which is close to the peak blocking frequency in NCEP-CFSR and CONTROL and also the region which exhibits the largest difference between the CONTROL and SMOOTH simulations (Figure 3). The index was produced using the 8-day low-pass filtered 6-hourly Z500 anomaly (using Z250 yields essentially the same results), averaged over the region $0^{\circ}-10^{\circ} \mathrm{E}$ and $60^{\circ}-65^{\circ} \mathrm{N}$. This is located slightly north of the storm track axis, to ensure we are identifying blocking highs that actively block the typical migration of weather systems. This continuous index is used in combination with the binary index (used in section 3) to identify blocking highs centred in time and space on the index region at times when the binary index identifies a blocking event. The continuous geopotential height index creates clearer composite maps than is possible using the binary index alone. Similar continuous indices have previously proved to be effective in identifying the characteristic quasi-stationary pattern that typically develops prior to wintertime European blocking (Nakamura, 1994; Nakamura et al., 1997). A minor limitation of this method is that jet speed over the North Atlantic is weaker during blocking events, so during periods leading to blocking we expect by definition to have higher jet speeds. Nonetheless, this compositing method is effective for analysing typical European blocking development. 
The 31 and 20 events (corresponding to the number of winters in each dataset) that have the highest peak geopotential height anomaly in the continuous index were selected to produce composites for NCEP-CFSR and the AGCM simulations, respectively (after discarding events that occur within two weeks of a stronger peak). More events are used in the NCEP-CFSR composites owing to the longer data period. During the course of this study, a number of index locations were tested, and moderate shifts in latitude (i.e. $\left.+/-5^{\circ}\right)$ as well as shifts downstream within the peak blocking region (up to $20^{\circ}$ further east) result in composites with similar evolution characteristics. For example, the index point of Nakamura et al. (1997) is located about $5^{\circ}$ further to the east and south of our index yet they observe blocking evolution, in a reanalysis dataset, very similar to that presented below.

\subsection{Upper-troposphere blocking development}

To visualise the development of the composite blocking anomalies, we will first analyse the evolution of isobaric PV at $300 \mathrm{hPa}$. The left column of Figure 8 shows the PV contours for the NCEP-CFSR blocking composite. Between 7 and 5 days prior to the index peak, there is little sign of any obvious PV anomaly. However, between 4 and 2 days prior to the blocking event, a strong ridge is already developing east of the Gulf Stream (indicated by the 8,12 and $16{ }^{\circ} \mathrm{C}$ isotherms in red contours), over the Atlantic Ocean. The PV gradient upstream of the ridge closely follows the Gulf Stream and turns north at the eastern edge of the Gulf Stream front. In snapshots of the PV there is an extremely sharp gradient across the dynamical tropopause (i.e. $\mathrm{PV}=2 \mathrm{PVU}$ ), in the vicinity of the North Atlantic jet. Hence, the tight composite PV gradient upstream of the ridge indicates that there is relatively little spread between the composite members in this region, corresponding to a consistent southwesterly jet extending from the end of the Gulf Stream front. Around the period of the blocking index peak (i.e. -1 to +1 days), the ridge that is seen developing between -4 and -2 days has overturned anticyclonically, as 
highlighted in previous studies (Nakamura 1994; Nakamura et al 1997; Tyrlis and Hoskins 2008b), and a large-scale low PV centre has become cut-off over Northern Europe. The gradient of the composite PV in the upstream flank of the ridge between -1 and +1 days is not as sharp as seen between -4 and -2 days but is very sharp to the north of the low PV centre, where the jet is diverted poleward of Europe by the blocking anomaly. By 2 to 4 days after the index peak, the blocking anomaly is less well defined, likely reflecting a weakening of the blocking anomalies and increased composite spread.

Figure 8 also shows the evolution of the upper-level PV in the CONTROL and SMOOTH simulations. The CONTROL simulation displays very similar behaviour to NCEPCFSR, with the ridge developing strongly between -4 and -2 days relative to the index peak. The sharp composite PV gradient and the southwesterly jet extending from the eastern edge of the Gulf Stream front is also clearly captured prior to the blocking onset. The anticyclonic overturning of the upper-level wave at blocking onset in CONTROL is not quite as pronounced as in NCEP-CFSR but nonetheless apparent, with a well-defined low PV centre over the North Sea. The SMOOTH simulation exhibits markedly different development, with a ridge between 4 and -2 days of shorter zonal extent than that present in CONTROL or NCEP-CFSR. The upstream flank of the ridge in SMOOTH exhibits a much weaker composite PV gradient than CONTROL or NCEP-CFSR (although a strong gradient is still seen in the region of the mean jet close to the entrance of the Atlantic storm track). The weaker PV gradient indicates a wider composite spread than in NCEP-CFSR and CONTROL and no clear, consistent southwesterly jet is present. Between -1 and +1 days the anticyclonic overturning is also present in the SMOOTH composite, however there is a pronounced trough on the upstream side of the ridge that is reminiscent of composite blocking development over the North Pacific (Nakamura et al. 1997). The low PV centre over the North Sea is less well defined in the SMOOTH composites, indicating there is less consistent large-scale cut-offs of low PV. 
The most obvious difference during the composite PV evolution over the period of the blocking events occurs in the upstream region during the development of the blocking ridge. The strong composite PV gradient in the upstream flank of the ridge between -4 and -2 days implies little spread between the composite members, as previously noted, but it also suggests that the position of the upstream flank remains approximately stationary over a period of several days. To demonstrate this more clearly, in Figure 9 the composite PV contour at approximately the dynamical tropopause (specifically PV=1.75 PVU in NCEP-CFSR and PV=2.25 PVU in AFES, owing to slight model bias) is plotted on each day relative to the index peak, for all three datasets (these contours are emboldened in Figure 8 for reference). As the ridge develops in NCEP-CFSR, the upstream flank remains in an approximately fixed position between -4 and -1 days, which is a clear indication of the quasi-stationary development highlighted in previous studies (e.g. Nakamura 1994; Nakamura et al 1997; Michelangeli and Vautard 1998; Altenhoff et al 2008). The CONTROL simulation displays similar quasi-stationary ridge development, with the position of the southwest-northeast orientated upstream flank remaining fixed between -4 and -1 days. On the peak index day, the upstream flank of the ridge moves downstream, possibly related to the overturning wave. The SMOOTH simulation, however, again displays a quite different evolution. From when the ridge becomes apparent at -4 days, it clearly moves downstream until -1 day when it becomes approximately stationary for the blocking peak, in contrast to the quasi-stationary behaviour seen in NCEP-CFSR and CONTROL. Moreover, the upstream flank in SMOOTH displays a distinctly meridional orientation, rather than the southwest-northeast orientation in NCEP-CFSR and CONTROL.

Since the difference of blocking development between the two simulations involves different behavior of the North Atlantic upper-level jet, which is largely driven by eddy momentum convergence along the storm track (e.g. Hoskins et al. 1983), it is intriguing to consider how the quasi-stationary development of blocking is related to storm track activity. It 
has previously been shown that eddy-forcing contributes to maintaining large-scale flow anomalies in the Atlantic sector, including blocking (e.g. Shutts et al. 1986).

To investigate the role of transient eddies in generating the differences in European blocking development, we first consider the evolution of the upper-level eddy kinetic energy.

Figure 10 shows the composite eddy kinetic energy (i.e. $\frac{1}{2}\left(u^{\prime 2}+v^{\prime 2}\right)$, where the velocities are 28 day band-pass filtered) at $300 \mathrm{hPa}$ for NCEP-CFSR. Between -7 and -5 days the eddy kinetic energy is close to its climatological value. Between -4 and -2 days the eddy kinetic energy is substantially larger than its climatology, particularly in the Gulf Stream region, and peaks around $40^{\circ} \mathrm{W}$, where the Gulf Stream turns north. Note, the peak in eddy kinetic energy is downstream from the peak in eddy kinetic energy generation (that occurs though baroclinic instability further upstream, see section 4.3), which is located to the east as is expected in the presence of a westerly background flow (Mak and Cai 1989). Between -4 and -2 days, the eddy kinetic energy in the Gulf Stream region peaks and after that reduces towards its climatological value. Between -1 and +1 days and between +2 and +4 days the eddy kinetic energy is anomalously high to the north of Europe, reflecting the deflection of the jet and associated advection of upper-level eddies due to the blocking anomaly.

Figure 11 shows the eddy kinetic energy composites for the CONTROL and SMOOTH simulations, as well as the DIFFERENCE (CONTROL minus SMOOTH as defined above). The CONTROL simulation overestimates the eddy kinetic energy compared to NCEP-CFSR but demonstrates very similar evolution. The eddy kinetic energy in CONTROL becomes strongly intensified in the Gulf Stream region between - 4 and -2 days and peaks on the eastern edge of the Gulf Stream front. The region of high eddy kinetic energy is fairly well constrained in the upstream flank of the developing ridge before reducing towards the climatological field between -1 and +1 days and between +2 and +4 days. In contrast, the SMOOTH composite eddy kinetic energy peaks between -7 and -5 days. Between -4 and -2 days the eddy kinetic energy field in the 
SMOOTH is located within the broad trough structure upstream of the ridge, and is again substantially less than in the CONTROL composite. As the blocking anomaly evolves further, the eddy kinetic energy in the SMOOTH is close to climatological values in the Gulf Stream region.

Figure 12 shows composite maps of $\mathbf{E} \cdot \mathbf{D}$ at $300 \mathrm{hPa}$ for NCEP-CFSR, CONTROL and SMOOTH. The quantity $\mathbf{E} \cdot \mathbf{D}$ is a measure of the generation of eddy kinetic energy from the kinetic energy of the background flow (defined here as the 8-day low-pass filtered flow ${ }^{1}$ ), such that negative values indicate that the kinetic energy of the eddies is feeding the background flow. The absolute value of the composite background wind velocity is shown in purple contours. In NCEP-CFSR and CONTROL the transfer of kinetic energy to the background flow peaks between -4 and -2 days, when the eddy kinetic energy also peaks (i.e. Figures 10 and 11). The eddies transfer most energy to the background flow in the narrow region where the jet turns north at the eastern edge of the Gulf Stream front, indicating that the eddies are actively reinforcing the jet in this position. There is substantially less eddy kinetic energy transferred to the mean flow in the SMOOTH simulation, in which the kinetic energy itself is also much lower in the build up to blocking compared with CONTROL (i.e. Figure 11). In the SMOOTH simulation, the region where the eddy forcing peaks between -4 and -2 days is located further west than the upstream flank of the developing ridge. Also, the jet upstream of the developing block is comparably weak and does not have the quasi-stationary southwesterly jet seen between -4 and -2 days in NCEP-CFSR and CONTROL, consistent with the aforementioned PV analysis (i.e. Figure 8).

The $\mathbf{E} \cdot \mathbf{D}$ fields indicate that the eddy kinetic energy intensification in the Gulf Stream region is important in determining the nature of European blocking onset. In NCEP-CFSR and

\footnotetext{
${ }^{1}$ Although the cut-off between eddy and low-pass variables is abrupt, E $\cdot \mathbf{D}$ maps produced with 2-6 day band pass filtered eddies and 8-day low-pass filtered background flows are qualitatively very similar.
} 
CONTROL, the eddies act to reinforce and enhance the southwesterly jet at upper-levels. The small scale of the region of peak eddy kinetic energy conversion is fairly remarkable given the three day averaging period (i.e. -4 to -2 days), implying that the eddies are important in maintaining the quasi-stationary southwesterly jet in this region. In the SMOOTH composites, the eddy kinetic energy fields are much weaker and there is weaker forcing of the low-frequency flow. To some extent the developing ridge has its own westward phase speed that acts to keep the wave stationary but the ridge development is not quasi-stationary in the SMOOTH case (i.e. Figure 10), suggesting that the feedback from the intensified storm track is crucially important for the quasi-stationary development seen in NCEP-CFSR and CONTROL.

\subsection{Lower-troposphere blocking development}

In this subsection we analyse activity in the lower-troposphere during European blocking development. The aforementioned intensification of the eddy kinetic energy field during blocking development in NCEP-CFSR and CONTROL suggests the presence of baroclinic instability, whose energy source is primarily the available potential energy (e.g. Lorenz 1955) but is also influenced by latent heat release (e.g. Ahmadi-Givi 2004; Willison et al. 2013). The growth of extratropical cyclones and associated storm tracks over the Atlantic peak close to the Gulf Stream (e.g. Hoskins and Hodges, 2002), which is a region of high baroclinicity and available moisture. To assess the storm track evolution we first analyse composites of the meridional eddy heat transport, $v^{\prime} T^{\prime}$, by synoptic eddies at $850 \mathrm{hPa}$ (calculated using a 2-8 day band-pass filter). The eddy heat flux is largest at $850 \mathrm{hPa}$ in the lower troposphere and peaks during the growth phase of baroclinic wave lifecycles (e.g. Simmons and Hoskins 1978). We will also investigate the composite precipitation associated with blocking development.

Figure 13 shows that meridional eddy heat transport in NCEP-CFSR exhibits evolution consistent with the eddy kinetic energy, shown in Figure 10, during blocking development. As 
with the upper-level eddy kinetic energy, the meridional eddy heat transport is close to the climatology between -7 and -5 days and then intensifies between -4 to -2 days along the Gulf Stream front and extends north, closely following the upstream flank of the ridge. The relatively fine scale of the meridional eddy heat transport composites indicate that the storm track seems to be effectively anchored by the Gulf Stream between -4 and -2 days. The peak in meridional eddy heat transport, and thereby eddy kinetic energy generation, between -4 and -2 days is located slightly upstream of the peak in eddy kinetic energy at $300 \mathrm{hPa}$ (i.e. Figure 10), as expected in the presence of a westerly mean flow (Mak and Cai 1989). After that, the meridional eddy heat transport is weakened between -1 and +1 days towards the climatology, as also seen in the upper-level eddy kinetic energy composites. The meridional eddy heat flux in CONTROL (Figure 14, left column) is slightly stronger than NCEP-CFSR (Figure 13), as also seen in the upper-level eddy kinetic energy, but the evolution is very similar, peaking between -4 and -2 days in close proximity to the Gulf Stream SST front.

The evolution of the eddy heat transport in the SMOOTH blocking composite (Figure 14, middle column) is, again, much different from NCEP-CFSR and CONTROL. The meridional eddy heat transport in SMOOTH is actually strongest between - 7 and -5 days in the storm track entrance region, whereas between -4 and -2 days the meridional eddy heat transport peak is weaker and located further downstream. The meridional eddy heat transport weakens further and retreats westward between -1 and +1 days. The DIFFERENCE (Figure 14, right column) reveals that the meridional eddy heat transport in SMOOTH is much weaker than in the CONTROL simulation and the location of the peak meridional eddy heat transport is noticeably less constrained by the smoothed SST front and instead migrates down stream. The meridional eddy heat flux analysis thus indicates that the storm track intensification over the Gulf Stream region during European blocking development, as seen in NCEP-CFSR and CONTROL, is strongly linked to the Gulf Stream SST front. The CONTROL simulation has a 
climatological wintertime storm track, not shown, that is similar in shape but about $25 \%$ stronger along the Gulf Stream front than in the SMOOTH simulation, similar to the simulations by Small et al. (2013).

Synoptic-scale eddies are largely dependent on background baroclinicity, but latent heat release associated with precipitation can enhance eddy activity (e.g. Ahmadi-Givi et al., 2004; Willison et al. 2013). Since the mean winter precipitation over the Atlantic exhibits a strong peak that is tightly constrained along the warm flank of the Gulf Stream (Minobe et al. 2008, 2010), it is interesting to investigate whether or not precipitation exhibits any systematic evolution during blocking development.

Figure 15 shows the composite precipitation for NCEP-CFSR. Between -7 and -5 days the precipitation is strong only in a band over the warm flank of the Gulf Stream SST front, similar to the wintertime climatology. As the ridge develops, between -4 and -2 days, the precipitation increases strongly over the eastern edge of the Gulf Stream and extends into the upstream flank of the ridge. The precipitation band remains strongly constrained by the Gulf Stream front, even as it turns north around $45^{\circ} \mathrm{W}$, and then weakens as it extends further north. Over the southern coast of Greenland, although quite strong precipitation occurs where the moist southerly flow rises steeply over the ice sheet, weak upper-level eddy kinetic energy (i.e. Figure 13) suggests this topographic precipitation does not contribute to upper-level eddy activity.

Figure 16 shows the precipitation composites for the CONTROL and SMOOTH simulations. The climatological precipitation in CONTROL is slightly too strong compared to NCEP-CFSR. However, the evolutions of the NCEP-CFSR and CONTROL precipitation fields are very similar. The rain band in CONTROL is again very clearly constrained by the Gulf Stream SST front and is also collocated with the tight PV gradient on the upstream flank of the developing ridge. In the SMOOTH simulation the precipitation band is generally weaker owing 
to the smoothed SST gradient, as found in previous modelling studies for annual or seasonal means (Minobe et al. 2008; Kuwano-Yoshida et al. 2010), but does still increase in the northward branch of the developing ridge between -4 and -2 days. The precipitation occurs over a broader region and is not closely constrained by the smoothed SST front.

The similarity of the evolution of the eddy activity in the upper troposphere, the meridional heat transport in the lower troposphere and the Gulf Stream precipitation during European blocking development should be emphasised. All of these fields exhibit a marked increase, which appears to be closely constrained by the Gulf Stream SST front, between - 4 and 2 days prior to the index peak in both NCEP-CFSR and CONTROL. In the SMOOTH composites the eddy activity in the upper and lower troposphere is much weaker and evolves quite differently. Also, the precipitation occurs over a much broader region during the development of blocking in the SMOOTH simulation.

These results indicate that both the eddy heat transport in the lower troposphere and precipitation, and thus latent heat release, are enhanced along the upstream flank of the developing ridge, at the eastern edge of the Gulf Stream. The enhanced regions are roughly collocated with the intensified upper-level eddy kinetic energy, described in the previous subsection, indicating that the enhanced lower-level storm track activity and precipitation act to energise the upper-level eddy field, which in turn shapes the quasi-stationary development of European blocking.

\section{Discussion and conclusions}

In this paper we have investigated the influence of the Gulf Stream SST front on European wintertime blocking using the NCEP-CFSR dataset and a pair of AGCM simulations, forced with realistic and smoothed Gulf Stream SST. Although the model underestimates the blocking frequency over Europe, it does effectively capture the distribution over Europe, which 
is found to depend crucially on the Gulf Stream SST front. In the absence of the sharp Gulf Stream SST front, European blocking is significantly reduced and more concentrated further downstream over Eastern Europe (Figure 3).

To determine the nature of the Gulf Stream influence on European blocking we analysed the evolution of composite European blocking events and found a consistent sequence of events leading to European blocking, as summarized in Figure 17. In NCEP-CFSR and CONTROL, the upstream flank of the developing ridge remains quasi-stationary, with a consistent southwesterly jet, for about 4-5 days prior to the index peak, whereas the SMOOTH simulation fails to capture the quasi-stationary development (Figures 8 and 9). The evolution seen in the NCEP-CFSR and CONTROL blocking composites is likely triggered by the arrival of an upper-level trough over the Gulf Stream region, which induces cyclogenesis ${ }^{2}$, increased eddy kinetic energy in the upper troposphere (Figures 10 and 11), increased meridional eddy heat flux in the lower troposphere (Figures 13 and 14) and intensified precipitation along the Gulf Stream SST front (Figures 15 and 16). The eddies transfer kinetic energy to the flow (Figure 12) on the upstream side of the trough, reinforcing the southwesterly jet, which remains quasi-stationary. If the storm track and eddy forcing remain strong in the Gulf Stream region, the southeasterly jet remains stationary and more low PV air is advected into the growing downstream ridge, ultimately resulting in European blocking. In the absence of the strong Gulf Stream SST gradient, as seen in the SMOOTH simulation, the eddy kinetic energy (Figure 11), meridional eddy heat flux (Figure 13), precipitation (Figure 15) and feedback by the transient eddies (Figure 12) are all weaker in the upstream region and ridge moves eastwards (Figure 9). In the absence of the strong south-westerly jet, less low PV air is advected into the ridge and as a result the PV anomaly is unable to counterbalance the westerly mean-flow. This is consistent with the peak

\footnotetext{
${ }^{2}$ This is type B cyclogenesis (e.g. Pettersen and Smebye 1971; Hoskins et al. 1985). Type A cyclogenesis also occurs close to the Gulf Stream (Gray and Dacre 2006) but more intense cyclogenesis in this region has been attributed to type B processes (Sanders 1986).
} 
blocking frequency in the SMOOTH simulation occurs further east, in a region of weaker mean westerly flow, where the phase speed of weaker low PV anomalies is able to become stationary and produce blocking events.

The surface temperature anomalies during European blocking periods are also shown to be quite different in the presence of the sharp Gulf Stream SST front. The Gulf Stream acts to generate more blocking anomalies over central Europe, where anomalous advection generates the coldest temperature anomalies (Figure 4). In the absence of the Gulf Stream the blocking anomalies tend to have more influence further downstream, over Eastern Europe. The subsequent influence on the European wintertime cold spell distribution is found to be significant (Figure 6). The cold spell peak, located along the northern coast of central Europe, depends crucially on the Gulf Stream and European blocking. With smoothed Gulf Stream SST the number of cold spell days over central Europe is significantly reduced. This is an interesting contrast to the popular notion that the heat transport by the Gulf Stream is responsible for the relatively mild European winters (e.g. Broeker 1997). Seager et al. (2002) previously suggested that the influence of the Gulf Stream on climatological surface temperatures is small (also the case in the AGCM experiments analysed here, as is apparent in Figure 2), and here we find that the Gulf Stream actually seems to be responsible for many of the extended spells of extremely cold surface temperature that occur over much of central Europe.

A previous study by Scaife et al. (2011) highlighted the importance of Atlantic SST on European blocking distribution, but the mechanism suggested in their study is not likely to play an important role in our AFES model. Scaife et al. attributed the majority of the improvement to a reduction in the bias of the North Atlantic jet, which was initially too strong in the presence of a strong cold SST bias in the central North Atlantic. Other studies indicate that biases in the position and strength of the mean jet can influence the asymmetry in the direction of uppertropospheric wavebreaking and therefore blocking (e.g. Michel and Riviere 2013). Studying the 
relationship between jet biases and blocking frequency in a different climate model, Davini et al. (2013) found that correcting for SST biases did improve the jet biases in their model but did not particularly improve the negative bias in European blocking frequency. Comparing the zonally averaged mean jet in our model over the Atlantic sector (i.e. $60^{\circ} \mathrm{W}-10^{\circ} \mathrm{E}$, as in Scaife et al. (2011)) reveals very little difference between the CONTROL and SMOOTH simulations. In fact, at the $300 \mathrm{hPa}$ level the velocity in CONTROL is about $1 \mathrm{~m} / \mathrm{s}$ stronger at $55^{\circ} \mathrm{N}$ (not shown), suggesting that the mechanism for the difference in blocking frequency is not simply due to differences in the mean North Atlantic jet; rather, the storm track dynamics in the vicinity of the Gulf Stream play a crucial role. It is likely that the response of the atmosphere to the Gulf Stream SST distribution is linked to horizontal resolution, with a sufficiently high resolution necessary to respond correctly capture the storm track dynamics around the sharp Gulf Stream SST gradient (as well as correctly representing the storm track more generally, as showed by Willison et al. (2013)) and subsequent downstream blocking over Europe.

Although we have emphasized the importance in the Gulf Stream SST in European blocking evolution and frequency over Europe, it is interesting to consider why blocking occurs less frequently in the absence of the Gulf Stream SST front. In the PV composites of the SMOOTH simulation (Figure 8) there is a deepening trough upstream of the developing blocking anomaly. This development is reminiscent of blocking anomalies over the eastern North Pacific, where blocking forms through spontaneous interaction between synoptic eddies and an existing diffluent zonal flow, such as a weak ridge (M. Nakamura 1994; Nakamura et al. 1997). The increased European blocking frequency in the CONTROL simulation indicates that the systematic, quasi-stationary southwesterly jet that develops over the western Atlantic is more efficient at generating European blocking anomalies than the more spontaneous development that occurs in the SMOOTH simulation. The results here suggest that the quasi-stationary nature of blocking development is one possible reason why, in reanalysis data, the peak in 
midlatitude blocking frequency over Europe is over twice as large as the peak in blocking frequency over the North Pacific (using one-dimensional midlatitude indices). The Kuroshio Extension appears to influence blocking over the western North Pacific more indirectly (O’Reilly and Czaja, 2014).

The importance of the storm track and transient eddy forcing highlighted here appears to disagree with the findings of Nakamura et al. (1997), who showed that advection by the lowfrequency flow, after removing the component due to synoptic eddies, was sufficient to generate European blocking anomalies. However, their contour advection and barotropic simulations were initialised with the 8-day low-pass velocity and PV fields at -4 and -3 days, respectively. To make a simple comparison we followed the composite method of Nakamura et al. (1997), using only the low-pass filtered geopotential height index and omitting the binary index, and produced low-pass filtered composites using the NCEP-CFSR dataset. Figure 18 shows the 8day low-pass composite velocity and PV at - 4 days for the NCEP-CFSR blocking composite and an equivalent composite produced over the North Pacific (see caption of Figure 18 for further details). It is clear that the quasi-stationary southwesterly jet and developing ridge are already present over the North Atlantic at this time, associated with the storm track intensification over the Gulf Stream. This suggests that transient eddy forcing is not negligible during European blocking development but rather that the eddy-forcing is important further upstream and during a longer period prior to European blocking events compared to North Pacific blocking events.

\section{Acknowledgements}

During this study we benefitted from thought-provoking discussions with Dr. Akira Yamazaki and Dr. Masahiro Watanabe. This work was supported by the Japan Society for the Promotion of Science (Grant-in-Aid for Scientific Research 22106008, 26287110). 


\section{References}

Ahmadi-Givi, F., Graig, G. C., \& Plant, R. S. (2004). The dynamics of a midlatitude cyclone with very strong latent-heat release. Quarterly Journal of the Royal Meteorological Society, 130(596), 295323. doi: $10.1256 /$ qj.02.226

Altenhoff, A. M., Martius, O., Croci-Maspoli, M., Schwierz, C., \& Davies, H. C. (2008). Linkage of atmospheric blocks and synoptic-scale Rossby waves: a climatological analysis. Tellus A, 60(5), 1053-1063. doi: 10.1111/j.1600-0870.2008.00354.x

Anstey, J. A., Davini, P., Gray, L. J., Woollings, T. J., Butchart, N., Cagnazzo, C., . . Yang, S. (2013). Multi-model analysis of Northern Hemisphere winter blocking: Model biases and the role of resolution. Journal of Geophysical Research: Atmospheres, 118(10), 3956-3971. doi: 10.1002/jgrd.50231

Barnes, E. A., Slingo, J., \& Woollings, T. (2011). A methodology for the comparison of blocking climatologies across indices, models and climate scenarios. Climate Dynamics, 38(11-12), 24672481. doi: $10.1007 /$ s00382-011-1243-6

Barriopedro, D., García-Herrera, R., \& Trigo, R. (2010). Application of blocking diagnosis methods to general circulation models. Part I: A novel detection scheme. Climate Dynamics, 35(7-8), 13731391.

Berckmans, J., Woollings, T., Demory, M.-E., Vidale, P.-L., \& Roberts, M. (2013). Atmospheric blocking in a high resolution climate model: influences of mean state, orography and eddy forcing. Atmospheric Science Letters, 14(1), 34-40. doi: 10.1002/asl2.412

Berggren, R., Bolin, B., \& Rossby, C. G. (1949). An Aerological Study of Zonal Motion, its Perturbations and Break-down. Tellus, 1(2), 14-37.

Booth, J. F., Wang, S., \& Polvani, L. (2012). Midlatitude storms in a moister world: lessons from idealized baroclinic life cycle experiments. Climate Dynamics, 41(3-4), 787-802. doi: 
$10.1007 / \mathrm{s} 00382-012-1472-3$

Brachet, S., Codron, F., Feliks, Y., Ghil, M., Le Treut, H., \& Simonnet, E. (2012). Atmospheric Circulations Induced by a Midlatitude SST Front: A GCM Study. Journal of Climate, 25(6), 1847-1853. doi: 10.1175/jcli-d-11-00329.1

Brayshaw, D. J., Hoskins, B., \& Blackburn, M. (2008). The Storm-Track Response to Idealized SST Perturbations in an Aquaplanet GCM. Journal of the Atmospheric Sciences, 65(9), 2842-2860. doi: $10.1175 / 2008 j a s 2657.1$

Brayshaw, D. J., Hoskins, B., \& Blackburn, M. (2011). The Basic Ingredients of the North Atlantic Storm Track. Part II: Sea Surface Temperatures. Journal of the Atmospheric Sciences, 68(8), 1784-1805. doi: $10.1175 / 2011$ jas3674.1

Broecker, W. S. (1997). Thermohaline circulation, the Achilles heel of our climate system: Will manmade CO2 upset the current balance? Science, 278(5343), 1582-1588.

Buehler, T., Raible, C. C., \& Stocker, T. F. (2011). The relationship of winter season North Atlantic blocking frequencies to extreme cold or dry spells in the ERA-40. Tellus A, 63(2), 212-222. doi: 10.1111/j.1600-0870.2010.00492.x

Cai, M., Yang, S., Van den Dool, H., \& Kousky, V. (2007). Dynamical implications of the orientation of atmospheric eddies: a local energetics perspective. Tellus A, 59(1), 127-140.

Cione, J. J., Raman, S., \& Pietrafesa, L. J. (1993). The effect of Gulf Stream-induced baroclinicity on US East Coast winter cyclones. Monthly Weather Review, 121(2), 421-430.

Colucci, S. J. (1985). Explosive cyclogenesis and large-scale circulation changes: Implications for atmospheric blocking. Journal of the Atmospheric Sciences, 42(24), 2701-2717.

Colucci, S. J., \& Alberta, T. L. (1996). Planetary-scale climatology of explosive cyclogenesis and blocking. Monthly Weather Review, 124(11), 2509-2520.

Crum, F. X., \& Stevens, D. F. (1988). A case study of atmospheric blocking using isentropic analysis. Monthly Weather Review, 116(1), 223-241. 
Davini, P., Cagnazzo, C., Fogli, P. G., Manzini, E., Gualdi, S., \& Navarra, A. (2013). European blocking and Atlantic jet stream variability in the NCEP/NCAR reanalysis and the CMCC-CMS climate model. Climate Dynamics, 43(1-2), 71-85. doi: 10.1007/s00382-013-1873-y

Davini, P., Cagnazzo, C., Gualdi, S., \& Navarra, A. (2012). Bidimensional Diagnostics, Variability, and Trends of Northern Hemisphere Blocking. Journal of Climate, 25(19), 6496-6509. doi: 10.1175/jcli-d-12-00032.1

Deremble, B., Lapeyre, G., \& Ghil, M. (2012). Atmospheric Dynamics Triggered by an Oceanic SST Front in a Moist Quasigeostrophic Model. Journal of the Atmospheric Sciences, 69(5), 1617-1632. doi: 10.1175/jas-d-11-0288.1

Doblas-Reyes, F. J. (2002). Sensitivity of the Northern Hemisphere blocking frequency to the detection index. Journal of Geophysical Research, 107(D2). doi: 10.1029/2000jd000290

Duchon, C. E. (1979). Lanczos filtering in one and two dimensions. Journal of Applied Meteorology, 18(8), 1016-1022.

Emanuel, K. A., \& Živkovic-Rothman, M. (1999). Development and evaluation of a convection scheme for use in climate models. Journal of the Atmospheric Sciences, 56(11), 1766-1782.

Enomoto, T., Kuwano-Yoshida, A., Komori, N., \& Ohfuchi, W. (2008). Description of AFES 2: Improvements for high-resolution and coupled simulations High Resolution Numerical Modelling of the Atmosphere and Ocean (pp. 77-97): Springer.

Gray, S. L., \& Dacre, H. F. (2006). Classifying dynamical forcing mechanisms using a climatology of extratropical cyclones. Quarterly Journal of the Royal Meteorological Society, 132(617), 11191137. doi: $10.1256 /$ qj.05.69

Hand, R., Keenlyside, N., Omrani, N.-E., \& Latif, M. (2013). Simulated response to inter-annual SST variations in the Gulf Stream region. Climate Dynamics, 42(3-4), 715-731. doi: 10.1007/s00382$013-1715-y$

Hoskins, B. (1997). A potential vorticity view of synoptic development. Meteorological Applications, 4(4), 
325-334.

Hoskins, B. J., \& Hodges, K. I. (2002). New perspectives on the Northern Hemisphere winter storm tracks. Journal of the Atmospheric Sciences, 59(6), 1041-1061.

Hoskins, B. J., James, I. N., \& White, G. H. (1983). The shape, propagation and mean-flow interaction of large-scale weather systems. Journal of the Atmospheric Sciences, 40(7), 1595-1612.

Hoskins, B. J., McIntyre, M., \& Robertson, A. W. (1985). On the use and significance of isentropic potential vorticity maps. Quarterly Journal of the Royal Meteorological Society, 111(470), 877946.

Huynen, M.-M., Martens, P., Schram, D., Weijenberg, M. P., \& Kunst, A. E. (2001). The impact of heat waves and cold spells on mortality rates in the Dutch population. Environmental health perspectives, 109(5), 463.

Illari, L., \& Marshall, J. C. (1983). On the interpretation of eddy fluxes during a blocking episode. Journal of the Atmospheric Sciences, 40(9), 2232-2242.

Jung, T., Miller, M. J., Palmer, T. N., Towers, P., Wedi, N., Achuthavarier, D., .. Hodges, K. I. (2012). High-Resolution Global Climate Simulations with the ECMWF Model in Project Athena: Experimental Design, Model Climate, and Seasonal Forecast Skill. Journal of Climate, 25(9), 3155-3172. doi: 10.1175/jcli-d-11-00265.1

Klein Tank, A. M. G., Wijngaard, J. B., K?nnen, G. P., B?hm, R., Demar?e, G., Gocheva, A., ... Petrovic, P. (2002). Daily dataset of 20th-century surface air temperature and precipitation series for the European Climate Assessment. International Journal of Climatology, 22(12), 1441-1453. doi: 10.1002/joc.773

Kuwano-Yoshida, A. (2014). Using the Local Deepening Rate to Indicate Extratropical Cyclone Activity. SOLA, 10, 199-203.

Kuwano-Yoshida, A., \& Enomoto, T. (2013). Predictability of explosive cyclogenesis over the northwestern Pacific region using ensemble reanalysis. Monthly Weather Review, 141(11), 3769- 
3785.

Kuwano-Yoshida, A., Enomoto, T., \& Ohfuchi, W. (2010). An improved PDF cloud scheme for climate simulations. Quarterly Journal of the Royal Meteorological Society, 136(651), 1583-1597. doi: $10.1002 / q j .660$

Kuwano-Yoshida, A., Minobe, S., \& Xie, S.-P. (2010). Precipitation Response to the Gulf Stream in an Atmospheric GCM*. Journal of Climate, 23(13), 3676-3698. doi: 10.1175/2010jcli3261.1

Lee, S.-S., Lee, J.-Y., Wang, B., Ha, K.-J., Heo, K.-Y., Jin, F.-F., . . Shukla, J. (2011). Interdecadal changes in the storm track activity over the North Pacific and North Atlantic. Climate Dynamics, 39(1-2), 313-327. doi: 10.1007/s00382-011-1188-9

Lorenz, E. N. (1955). Available potential energy and the maintenance of the general circulation. Tellus, $7(2), 157-167$.

Luo, D., Cha, J., Zhong, L., \& Dai, A. (2014). A nonlinear multiscale interaction model for atmospheric blocking: The eddy-blocking matching mechanism. Quarterly Journal of the Royal Meteorological Society, 140(683), 1785-1808. doi: 10.1002/qj.2337

Mak, M., \& Cai, M. (1989). Local barotropic instability. Journal of the Atmospheric Sciences, 46(21), 3289-3311.

Masato, G., Hoskins, B. J., \& Woollings, T. (2013). Winter and Summer Northern Hemisphere Blocking in CMIP5 Models. Journal of Climate, 26(18), 7044-7059. doi: 10.1175/jcli-d-12-00466.1

Masato, G., Hoskins, B. J., \& Woollings, T. J. (2009). Can the Frequency of Blocking Be Described by a Red Noise Process? Journal of the Atmospheric Sciences, 66(7), 2143-2149. doi: $10.1175 / 2008 j a s 2907.1$

Masato, G., Hoskins, B. J., \& Woollings, T. J. (2012). Wave-breaking characteristics of midlatitude blocking. Quarterly Journal of the Royal Meteorological Society, 138(666), 1285-1296. doi: 10.1002/qj.990

Masato, G., Woollings, T., \& Hoskins, B. J. (2014). Structure and impact of atmospheric blocking over 
the Euro-Atlantic region in present-day and future simulations. Geophysical Research Letters, 41(3), 1051-1058. doi: 10.1002/2013gl058570

Matsueda, M., Mizuta, R., \& Kusunoki, S. (2009). Future change in wintertime atmospheric blocking simulated using a 20-km-mesh atmospheric global circulation model. Journal of Geophysical Research, 114(D12). doi: 10.1029/2009jd011919

Michel, C., \& Rivière, G. (2014). Sensitivity of the Position and Variability of the Eddy-Driven Jet to Different SST Profiles in an Aquaplanet General Circulation Model. Journal of the Atmospheric Sciences, 71(1), 349-371. doi: 10.1175/jas-d-13-074.1

Michel, C., Rivière, G., Terray, L., \& Joly, B. (2012). The dynamical link between surface cyclones, uppertropospheric Rossby wave breaking and the life cycle of the Scandinavian blocking. Geophysical Research Letters, 39(10), n/a-n/a. doi: 10.1029/2012gl051682

Michelangeli, P. A., \& Vautard, R. (1998). The dynamics of Euro-Atlantic blocking onsets. Quarterly Journal of the Royal Meteorological Society, 124(548), 1045-1070.

Minobe, S., Kuwano-Yoshida, A., Komori, N., Xie, S. P., \& Small, R. J. (2008). Influence of the Gulf Stream on the troposphere. Nature, 452(7184), 206-209. doi: 10.1038/nature06690

Minobe, S., Miyashita, M., Kuwano-Yoshida, A., Tokinaga, H., \& Xie, S.-P. (2010). Atmospheric Response to the Gulf Stream: Seasonal Variations*. Journal of Climate, 23(13), 3699-3719. doi: $10.1175 / 2010$ jcli3359.1

Minobe, S., \& Takebayashi, S. (2014). Diurnal precipitation and high cloud frequency variability over the Gulf Stream and over the Kuroshio. Climate Dynamics. doi: 10.1007/s00382-014-2245-y

Nakamura, H. (1994). Rotational evolution of potential vorticity associated with a strong blocking flow configuration over Europe. Geophysical Research Letters, 21(18), 2003-2006.

Nakamura, H., Nakamura, M., \& Anderson, J. L. (1997). The role of high-and low-frequency dynamics in blocking formation. Monthly Weather Review, 125(9), 2074-2093.

Nakamura, H., Sampe, T., Goto, A., Ohfuchi, W., \& Xie, S.-P. (2008). On the importance of midlatitude 
oceanic frontal zones for the mean state and dominant variability in the tropospheric circulation. Geophysical Research Letters, 35(15). doi: 10.1029/2008gl034010

Nakamura, H., \& Wallace, J. M. (1990). Observed changes in baroclinic wave activity during the life cycles of low-frequency circulation anomalies. Journal of the Atmospheric Sciences, 47(9), 11001116.

Nakamura, H., \& Wallace, J. M. (1993). Synoptic behavior of baroclinic eddies during the blocking onset. Monthly Weather Review, 121(7), 1892-1903.

Nakamura, M. (1994). Characteristics of potential vorticity mixing by breaking Rossby waves in the vicinity of a jet. Massachusetts Institute of Technology.

Namias, J. (1947). Characteristics of the general circulation over the Northern Hemisphere during the abnormal winter 1946-47. Mon Weather Rev, 75(8), 145-152.

O'Reilly, C. H., \& Czaja, A. (2014). The response of the Pacific storm track and atmospheric circulation to Kuroshio Extension variability. Quarterly Journal of the Royal Meteorological Society, n/a-n/a. doi: $10.1002 / q j .2334$

Ogawa, F., Nakamura, H., Nishii, K., Miyasaka, T., \& Kuwano-Yoshida, A. (2012). Dependence of the climatological axial latitudes of the tropospheric westerlies and storm tracks on the latitude of an extratropical oceanic front. Geophysical Research Letters, 39(5).

Ohfuchi, W., Nakamura, H., Yoshioka, M. K., Enomoto, T., Takaya, K., Peng, X., . . Ninomiya, K. (2004). 10-km mesh meso-scale resolving simulations of the global atmosphere on the Earth Simulator: Preliminary outcomes of AFES (AGCM for the Earth Simulator). J. Earth Simulator, $1,8-34$.

Pelly, J. L., \& Hoskins, B. J. (2003). A new perspective on blocking. Journal of the Atmospheric Sciences, 60(5), 743-755.

Petterssen, S., \& Smebye, S. J. (1971). On the development of extratropical cyclones. Quarterly Journal of the Royal Meteorological Society, 97(414), 457-482. 
Raible, C. C., Ziv, B., Saaroni, H., \& Wild, M. (2009). Winter synoptic-scale variability over the Mediterranean Basin under future climate conditions as simulated by the ECHAM5. Climate Dynamics, 35(2-3), 473-488. doi: 10.1007/s00382-009-0678-5

Rex, D. F. (1950). Blocking action in the middle troposphere and its effect upon regional climate. Tellus, 2(4), 275-301.

Rex, D. F. (1951). The effect of Atlantic blocking action upon European climate. Tellus, 3(2), 100-112. Reynolds, R. W., Smith, T. M., Liu, C., Chelton, D. B., Casey, K. S., \& Schlax, M. G. (2007). Daily highresolution-blended analyses for sea surface temperature. Journal of Climate, 20(22), 5473-5496.

Saha, S., Moorthi, S., Pan, H.-L., Wu, X., Wang, J., Nadiga, S., . . Goldberg, M. (2010). The NCEP Climate Forecast System Reanalysis. Bulletin of the American Meteorological Society, 91(8), 1015-1057. doi: 10.1175/2010bams3001.1

Sampe, T., Nakamura, H., Goto, A., \& Ohfuchi, W. (2010). Significance of a Midlatitude SST Frontal Zone in the Formation of a Storm Track and an Eddy-Driven Westerly Jet*. Journal of Climate, 23(7), 1793-1814. doi: 10.1175/2009jcli3163.1

Sanders, F. (1986). Explosive cyclogenesis in the west-central North Atlantic Ocean, 1981-84. Part I: Composite structure and mean behavior. Monthly Weather Review, 114(10), 1781-1794.

Scaife, A. A., Copsey, D., Gordon, C., Harris, C., Hinton, T., Keeley, S., ... Williams, K. (2011). Improved Atlantic winter blocking in a climate model. Geophysical Research Letters, 38(23), n/an/a. doi: $10.1029 / 2011$ gl049573

Scaife, A. A., Woollings, T., Knight, J., Martin, G., \& Hinton, T. (2010). Atmospheric Blocking and Mean Biases in Climate Models. Journal of Climate, 23(23), 6143-6152. doi: 10.1175/2010jcli3728.1

Seager, R., Battisti, D. S., Yin, J., Gordon, N., Naik, N., Clement, A. C., \& Cane, M. A. (2002). Is the Gulf Stream responsible for Europe's mild winters? Quarterly Journal of the Royal Meteorological Society, 128(586), 2563-2586. doi: 10.1256/qj.01.128

Shutts, G. (1983). The propagation of eddies in diffluent jetstreams: Eddy vorticity forcing of 
'blocking'flow fields. Quarterly Journal of the Royal Meteorological Society, 109(462), 737-761.

Shutts, G. (1986). A case study of eddy forcing during an Atlantic blocking episode. Advances in Geophysics, 29, 135-162.

Sillmann, J., Croci-Maspoli, M., Kallache, M., \& Katz, R. W. (2011). Extreme Cold Winter Temperatures in Europe under the Influence of North Atlantic Atmospheric Blocking. Journal of Climate, 24(22), 5899-5913. doi: 10.1175/2011jcli4075.1

Simmons, A. J., \& Hoskins, B. J. (1978). The life cycles of some nonlinear baroclinic waves. Journal of the Atmospheric Sciences, 35(3), 414-432.

Small, R. J., Tomas, R. A., \& Bryan, F. O. (2013). Storm track response to ocean fronts in a global highresolution climate model. Climate Dynamics, 43(3-4), 805-828. doi: 10.1007/s00382-013-1980-9

Swanson, K. (2001). Blocking as a local instability to zonally varying flows. Quarterly Journal of the Royal Meteorological Society, 127(574), 1341-1355.

Tibaldi, S., \& Molteni, F. (1990). On the operational predictability of blocking. Tellus A, 42(3), 343-365.

Trenberth, K. E. (1986). An assessment of the impact of transient eddies on the zonal flow during a blocking episode using localized Eliassen-Palm flux diagnostics. Journal of the Atmospheric Sciences, 43(19), 2070-2087.

Trigo, R. M., Trigo, I. F., DaCamara, C. C., \& Osborn, T. J. (2004). Climate impact of the European winter blocking episodes from the NCEP/NCAR Reanalyses. Climate Dynamics, 23(1). doi: $10.1007 / \mathrm{s} 00382-004-0410-4$

Tyrlis, E., \& Hoskins, B. J. (2008). The Morphology of Northern Hemisphere Blocking. Journal of the Atmospheric Sciences, 65(5), 1653-1665. doi: 10.1175/2007jas2338.1

Tyrlis, E., \& Hoskins, B. J. (2008). Aspects of a Northern Hemisphere Atmospheric Blocking Climatology. Journal of the Atmospheric Sciences, 65(5), 1638-1652. doi: 10.1175/2007jas2337.1

Virts, K. S., Wallace, J. M., L., H. M., \& Holzworth, R. H. (2015). Diurnal and seasonal lightning variability over the Gulf Stream and the Gulf of Mexico. Journal of the Atmospheric Sciences. 
Willison, J., Robinson, W. A., \& Lackmann, G. M. (2013). The Importance of Resolving Mesoscale Latent Heating in the North Atlantic Storm Track. Journal of the Atmospheric Sciences, 70(7), 2234-2250. doi: 10.1175/jas-d-12-0226.1

Woollings, T., Franzke, C., Hodson, D. L. R., Dong, B., Barnes, E. A., Raible, C. C., \& Pinto, J. G. (2014). Contrasting interannual and multidecadal NAO variability. Climate Dynamics. doi: $10.1007 / \mathrm{s} 00382-014-2237-y$

Woollings, T., Hoskins, B., Blackburn, M., Hassell, D., \& Hodges, K. (2009). Storm track sensitivity to sea surface temperature resolution in a regional atmosphere model. Climate Dynamics, 35(2-3), 341-353. doi: 10.1007/s00382-009-0554-3

Yamazaki, A., \& Itoh, H. (2013). Vortex-Vortex Interactions for the Maintenance of Blocking. Part I: The Selective Absorption Mechanism and a Case Study. Journal of the Atmospheric Sciences, 70(3), 725-742. doi: 10.1175/jas-d-11-0295.1

Yamazaki, A., \& Itoh, H. (2013). Vortex-Vortex Interactions for the Maintenance of Blocking. Part II: Numerical Experiments. Journal of the Atmospheric Sciences, 70(3), 743-766. doi: 10.1175/jas-d$12-0132.1$ 
(a) CONTROL

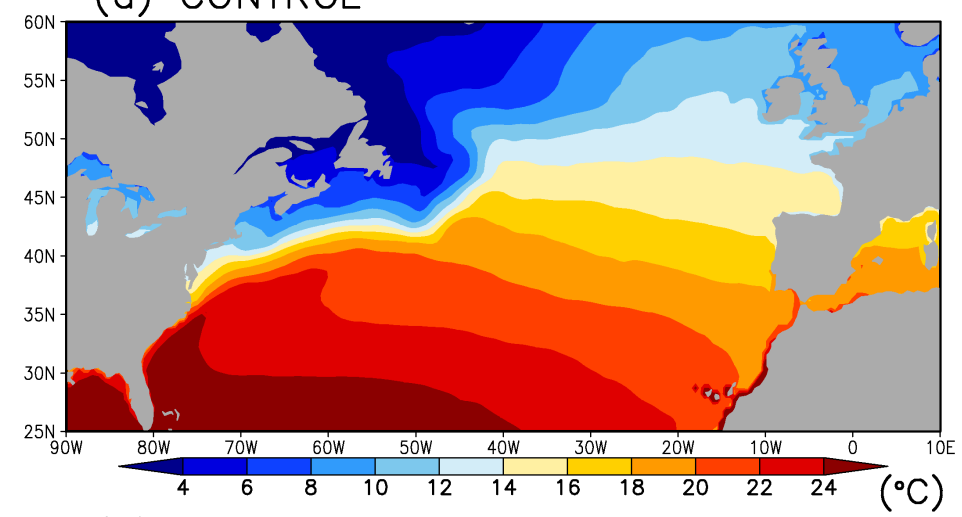

(b) SMOOTH

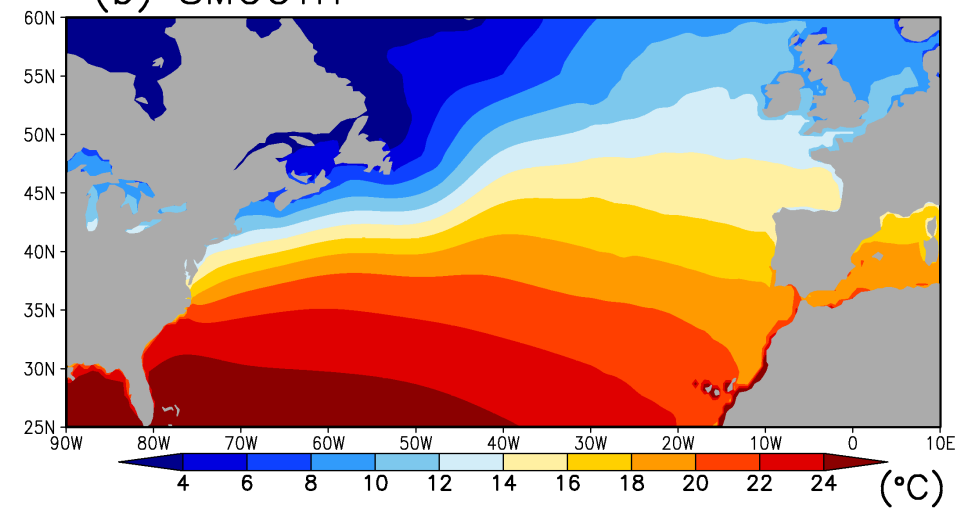

(c) DIFFERENCE

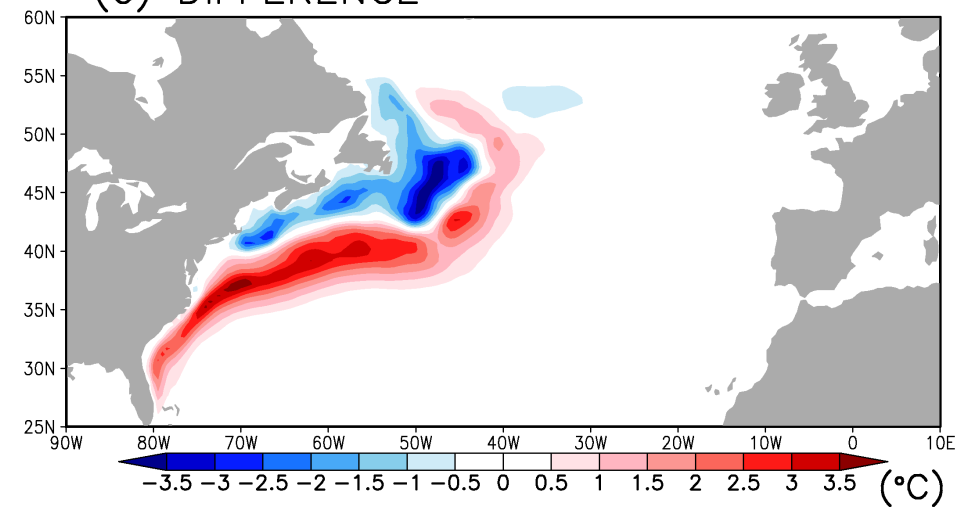

Figure 1. Wintertime (i.e. DJF) climatologies of the SST boundary condition used to in the (a) CONTROL and (b) SMOOTH simulations. The difference, CONTROL minus SMOOTH, is shown in (c). 
(a) $\mathrm{Z}(500 \mathrm{hPa})$ NCEP-CFSR

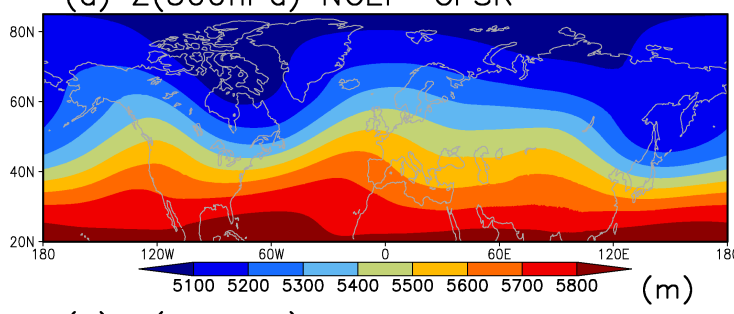

(b) $\mathrm{Z}(500 \mathrm{hPa})$ DIFFERENCE

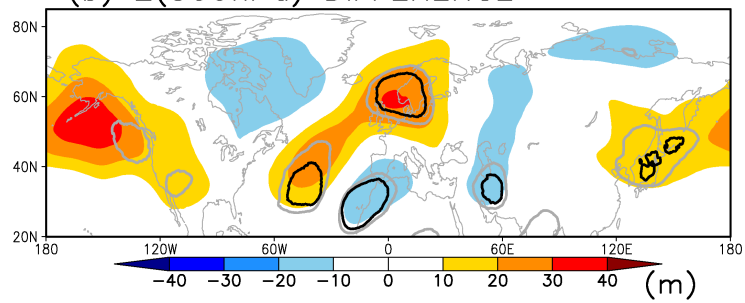

(c) $\mathrm{T}(2 \mathrm{~m})$ NCEP-CFSR

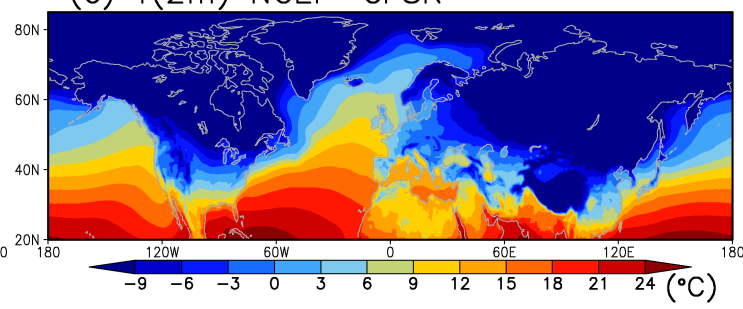

(d) $\mathrm{T}(2 \mathrm{~m})$ DIFFERENCE

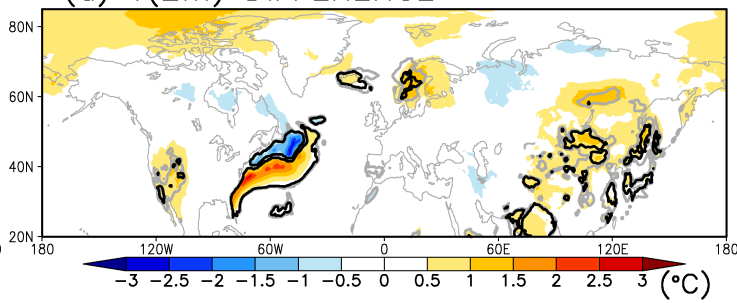

Figure 2. Wintertime (DJF) climatologies for the geopotential height, $Z$, at $500 \mathrm{hPa}$ (left column) and the temperature, $T$, at $2 \mathrm{~m}$ (right column) in the NCEP-CFSRdataset. Panels (b) and $(\mathrm{d})$ show the difference between the climatological fields in the AGCM experiments (defined as CONTROL minus SMOOTH). The thick grey and black contours indicate regions where the difference between the two experiments is greater that $90 \%$ and $95 \%$, respectively (according to a Monte Carlo resampling of the two datasets, as described in section 2.4). 


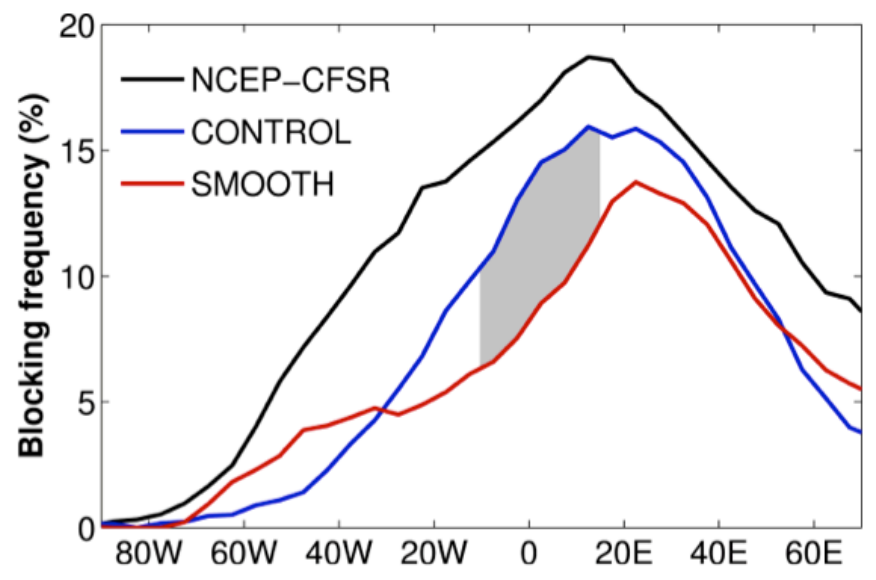

Figure 3. The wintertime (DJF) blocking frequencies in the NCEP-CFSR (black), CONTROL (blue) and SMOOTH (red). The grey shaded region indicates where the difference is significant at the $10 \%$ significance level. 
(a) NCEP-CFSR

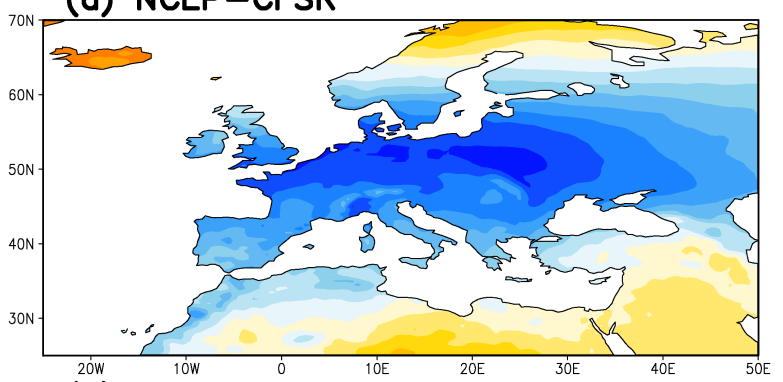

(b) CONTROL

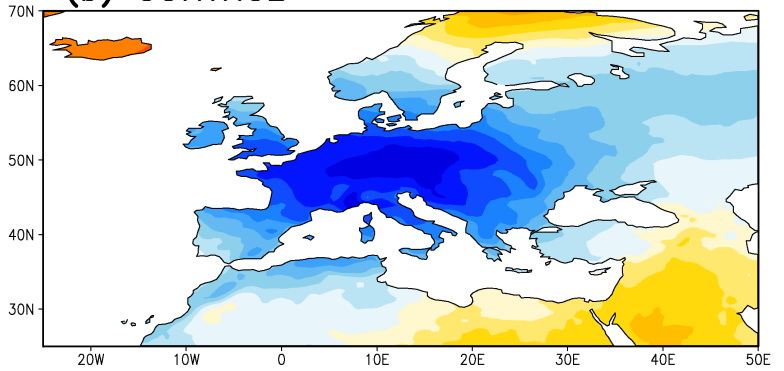

(c) SMOOTH

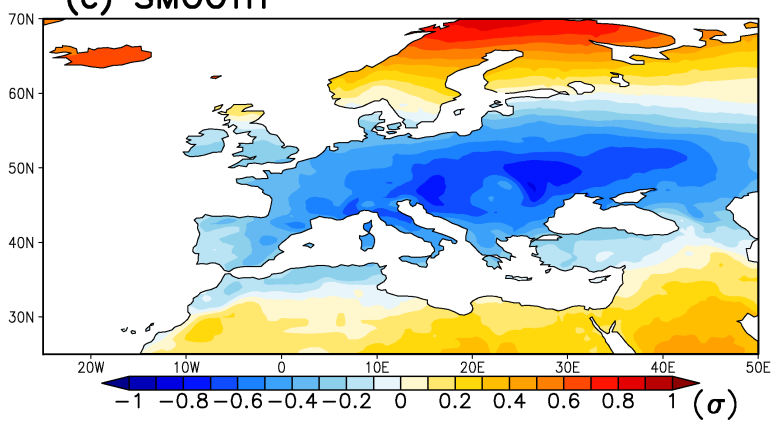

(d) DIFFERENCE

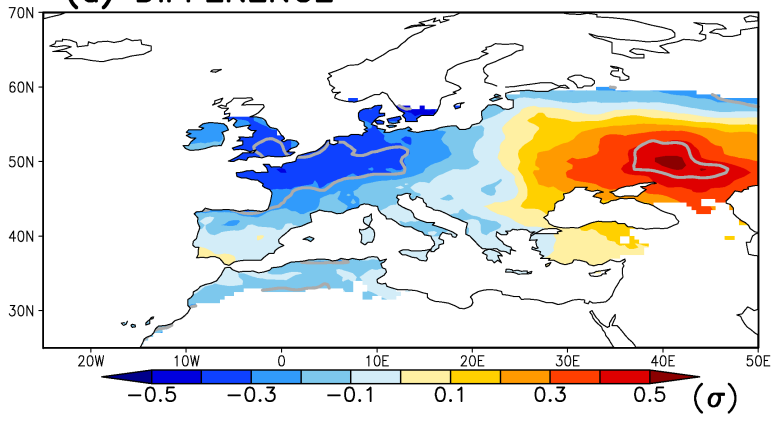

Figure 4. Normalised composite temperature anomaly during European blocking periods (between $20^{\circ} \mathrm{W}$ and $40^{\circ} \mathrm{E}$ ) for the (a) NCEP-CFSR, (b) CONTROL and (c) SMOOTH. The difference between the CONTROL and SMOOTH anomalies is shown in (d) and is only shaded where both exhibit cold anomalies. The grey contours denote regions where the difference is significant at the $10 \%$ significance level. 

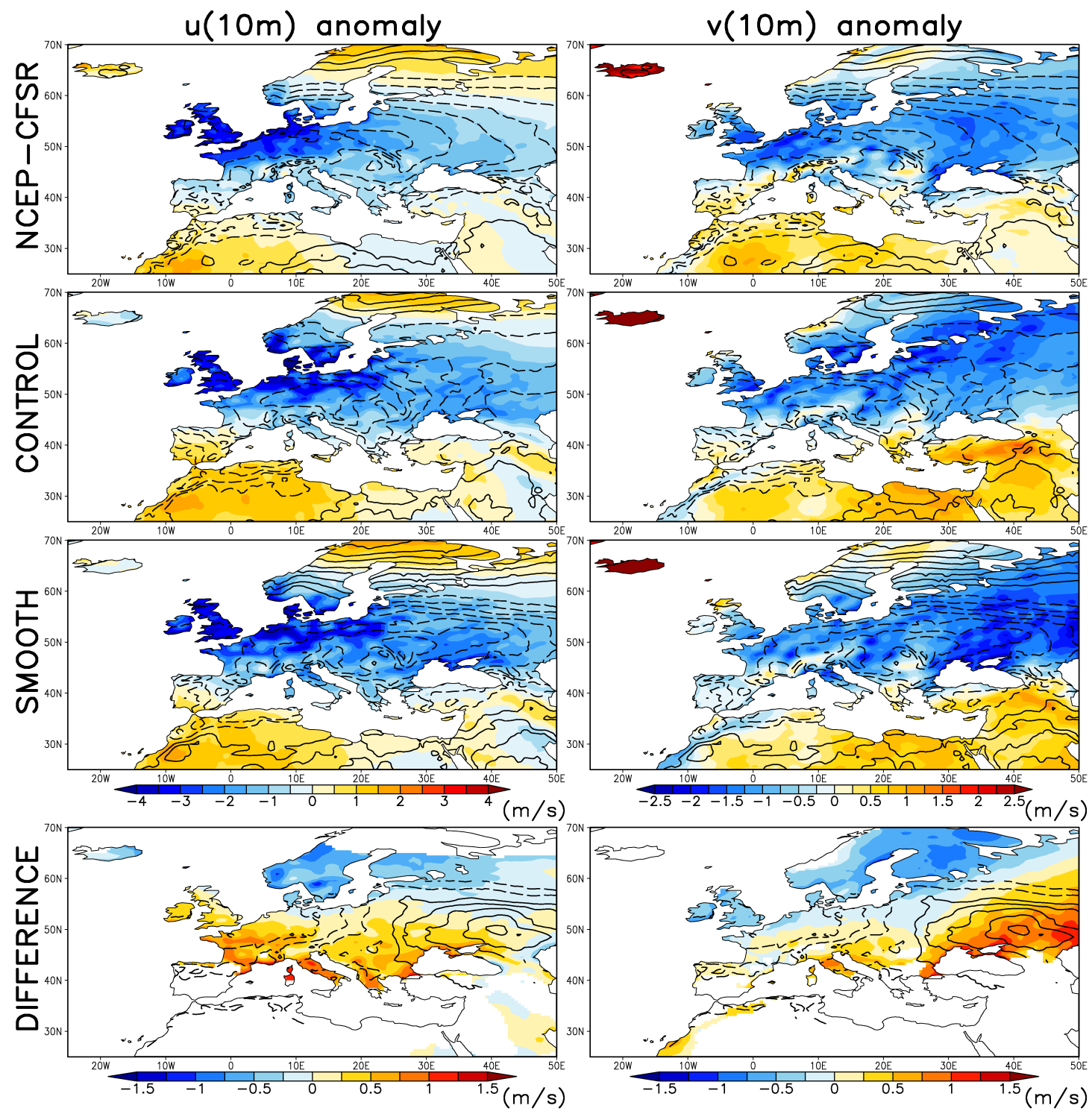

Figure 5. The composite $10 \mathrm{~m}$ zonal (left column) and meridional (right column) wind anomalies during European blocking periods (shading). The difference between the CONTROL and SMOOTH composites has only been shaded where both exhibit negative anomalies. For reference, the normalised composite temperature anomalies from Figure 4 are contoured (interval equal to 0.1 , where the zero contours are suppressed and the negative contours are dashed). 
(a) NCEP-CFSR

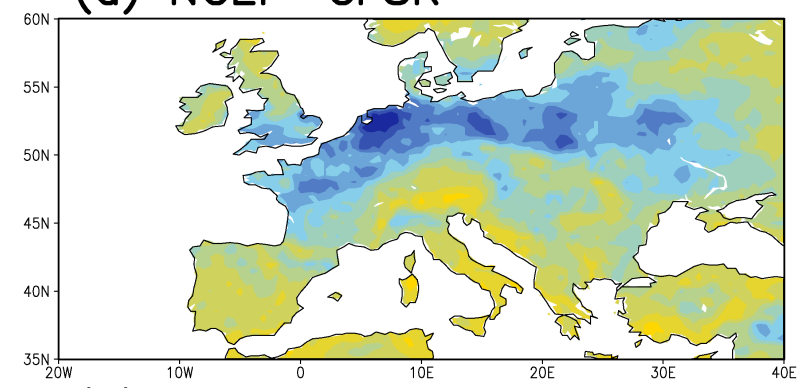

(b) CONTROL

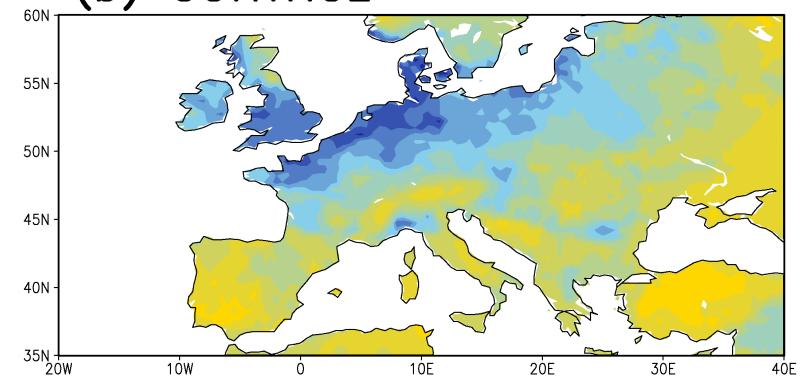

(c) SMOOTH

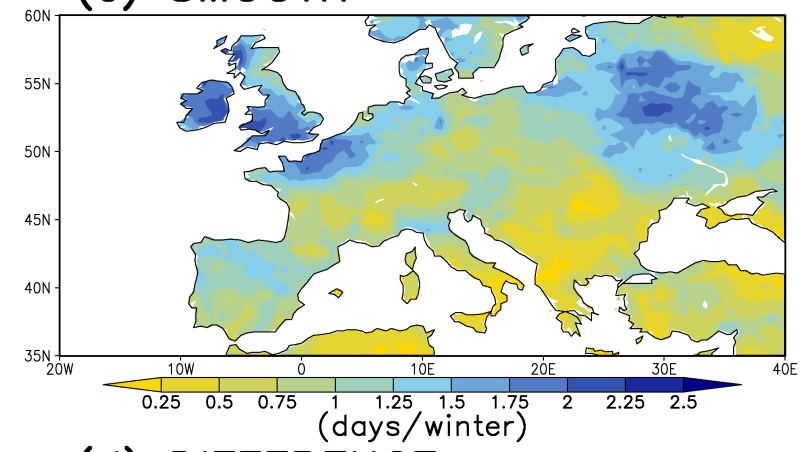

(d) DIFFERENCE

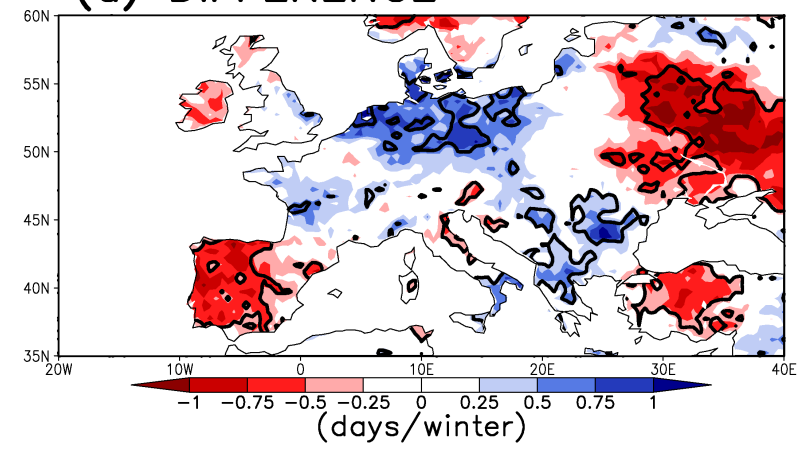

Figure 6. The number of cold-spell days per winter (as defined in the text) in (a) NCEP-CFSR, (b) CONTROL and (c) SMOOTH. The difference between the CONTROL and SMOOTH simulations is shown in (d), where black contours denote regions where the difference is significant at the $10 \%$ significance level. 


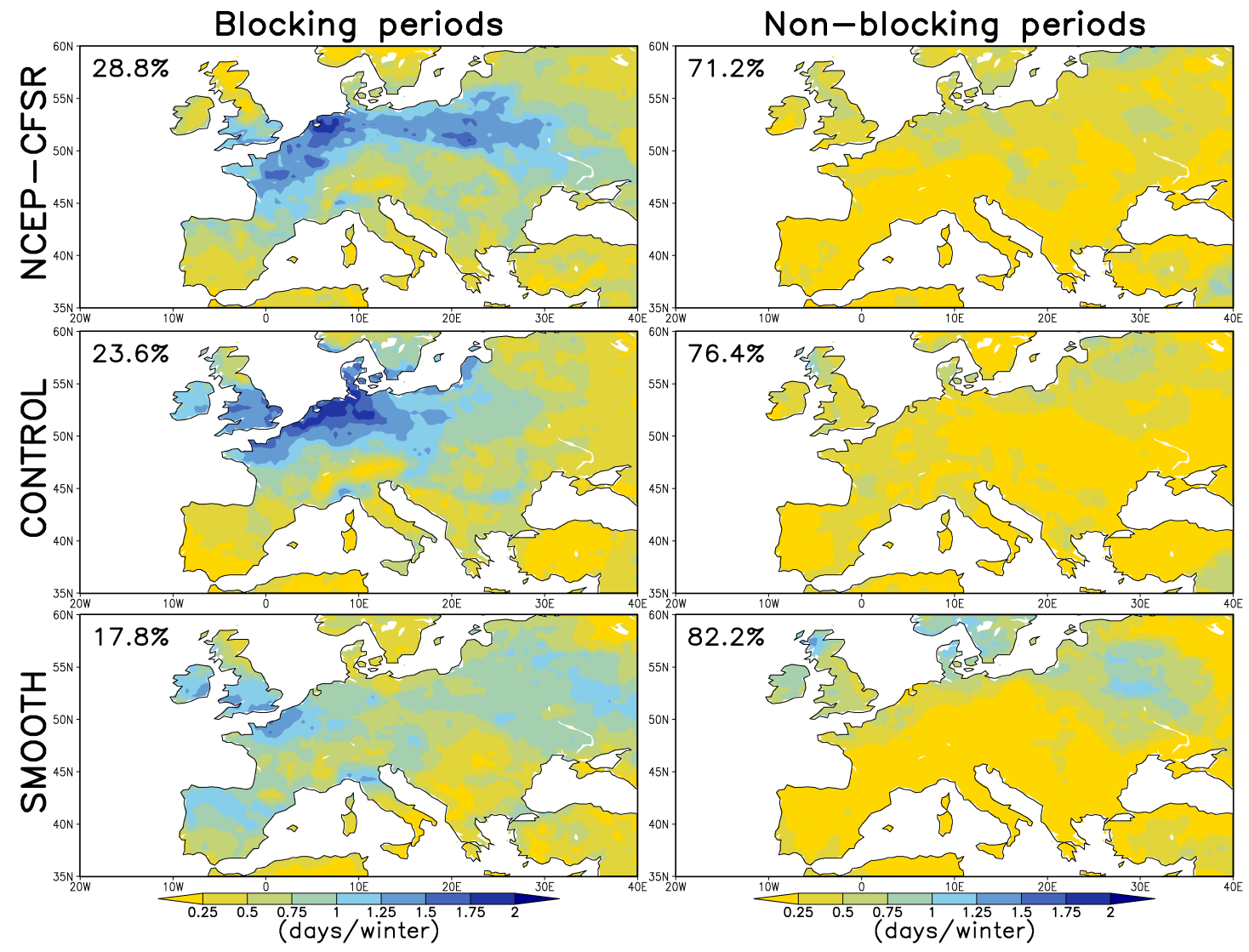

Figure 7. The contribution of blocking and non-blocking periods to the total cold spell maps shown in Figure 6. The percentage of total winter days is indicated in the top left corner of each map. 


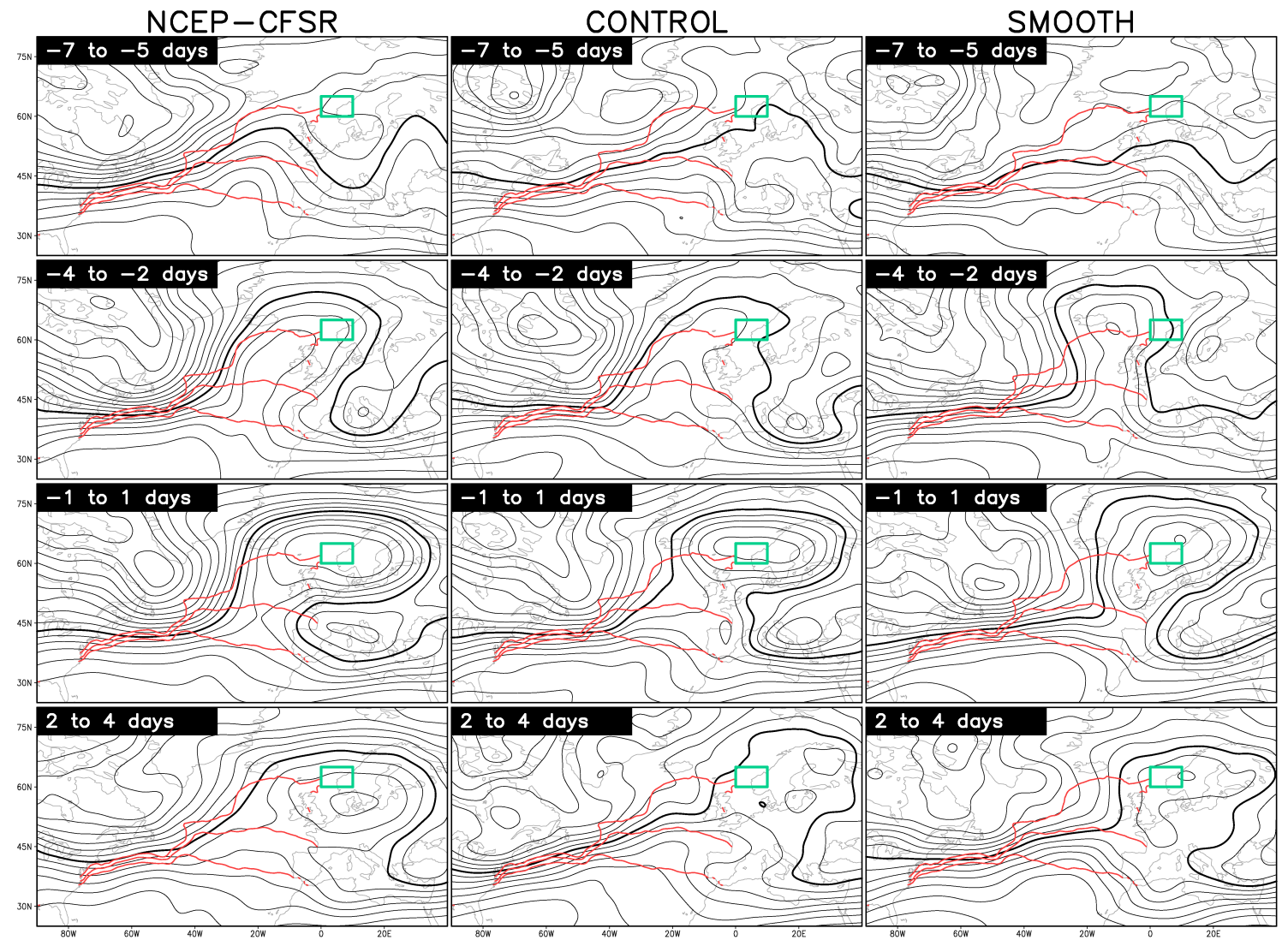

Figure 8. Evolution of the composite $\mathrm{PV}$ at $300 \mathrm{hPa}$ (black contours) along with wintertime SST (red contours). The PV contours start at 0.5 PVU with an interval of 0.25 PVU. The emboldened black contour is the 1.75 PVU contour in the NCEP-CFSR and 2.25 in the CONTROL and SMOOTH (these contours are plotted for reference in other composite figures). Contours for SST are plotted for $8^{\circ} \mathrm{C}, 12^{\circ} \mathrm{C}$ and $16^{\circ} \mathrm{C}$. The green box indicates the region used to produce the low-pass filtered geopotential height index. 
(a) NCEP-CFSR

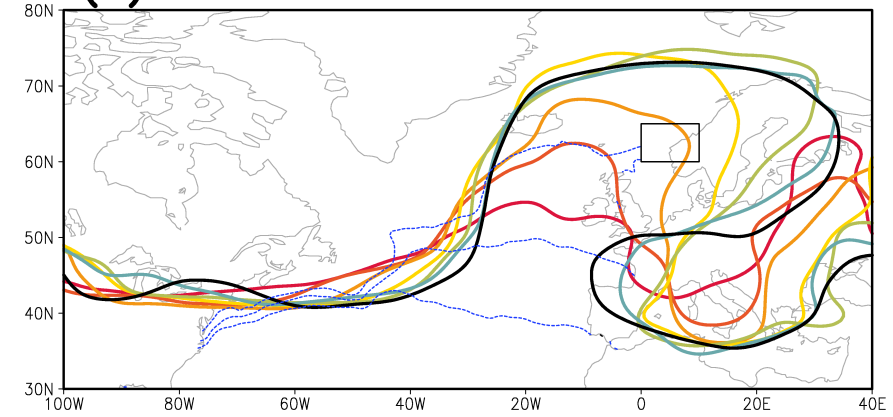

(b) CONTROL

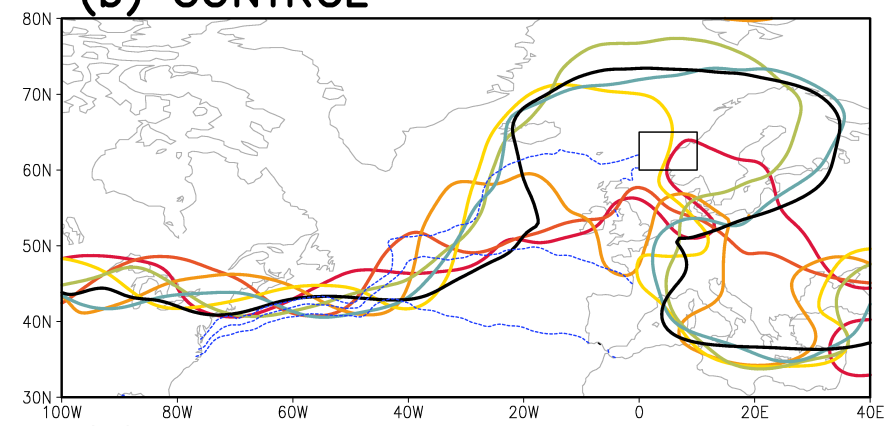

(c) SMOOTH

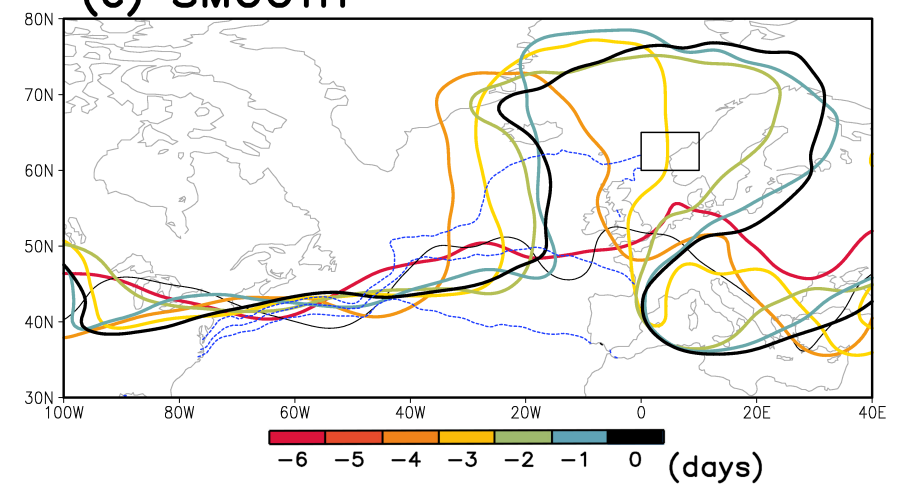

Figure 9. Evolution of a single PV contour close to the dynamical tropopause prior to the peak of the blocking index. The 1.75 PVU contour is plotted for the NCEP-CFSR and the 2.25 contour is plotted for the CONTROL and SMOOTH (these are the emboldened PV contours plotted in Figure 8). Wintertime SST contours are plotted in blue for $8^{\circ} \mathrm{C}, 12^{\circ} \mathrm{C}$ and $16^{\circ} \mathrm{C}$. The thin black box indicates the region used to produce the low-pass filtered geopotential height index. 


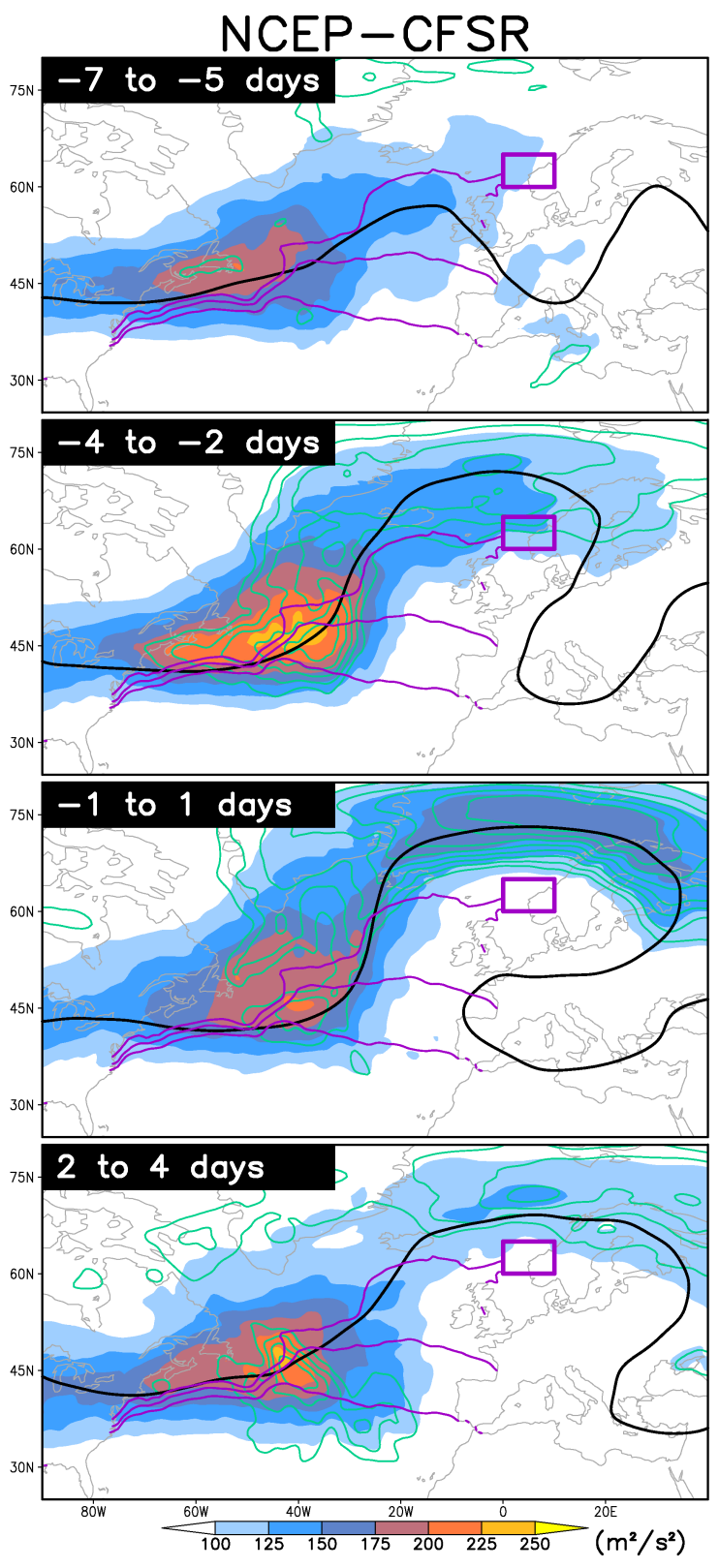

Figure 10. Evolution of the composite eddy kinetic energy at $300 \mathrm{hPa}$, shaded, in the NCEPCFSR. Positive anomalies, relative to climatology, are indicated in green contours, starting at 40 $\mathrm{m}^{2} / \mathrm{s}^{2}$ with an interval of $20 \mathrm{~m}^{2} / \mathrm{s}^{2}$. The thick black contour indicates where the composite $\mathrm{PV}$ at $300 \mathrm{hPa}$ is equal to $1.75 \mathrm{PVU}$. Wintertime SST contours are drawn in purple for for $8^{\circ} \mathrm{C}, 12^{\circ} \mathrm{C}$ and $16^{\circ} \mathrm{C}$. The thick purple box indicates the region used to produce the low-pass filtered geopotential height index. 


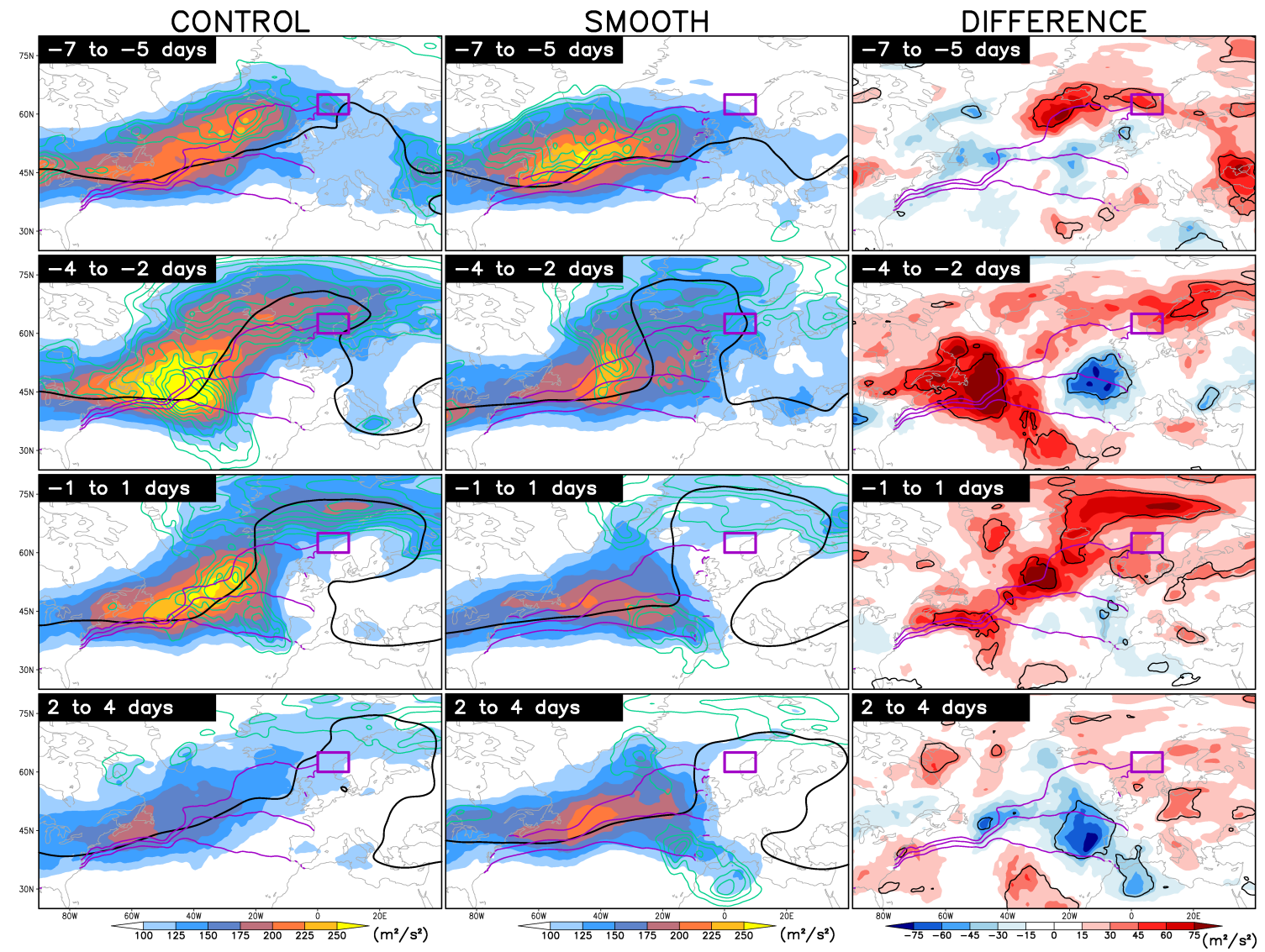

Figure 11. Evolution of the composite eddy kinetic energy at $300 \mathrm{hPa}$, shaded, in the CONTROL, SMOOTH and the DIFFERENCE, defined CONTROL minus SMOOTH. Positive anomalies, relative to the respective climatologies, are indicated in green contours, starting at 40 $\mathrm{m}^{2} / \mathrm{s}^{2}$ with an interval of $20 \mathrm{~m}^{2} / \mathrm{s}^{2}$. The thick black contour indicates where the composite PV at $300 \mathrm{hPa}$ is equal to $2.25 \mathrm{PVU}$. The thin black contours in the DIFFERENCE maps indicate regions where the difference between the composites is significant at the $10 \%$ significance level. Wintertime SST contours are drawn in purple for for $8^{\circ} \mathrm{C}, 12^{\circ} \mathrm{C}$ and $16^{\circ} \mathrm{C}$. The thick purple box indicates the region used to produce the low-pass filtered geopotential height index. 


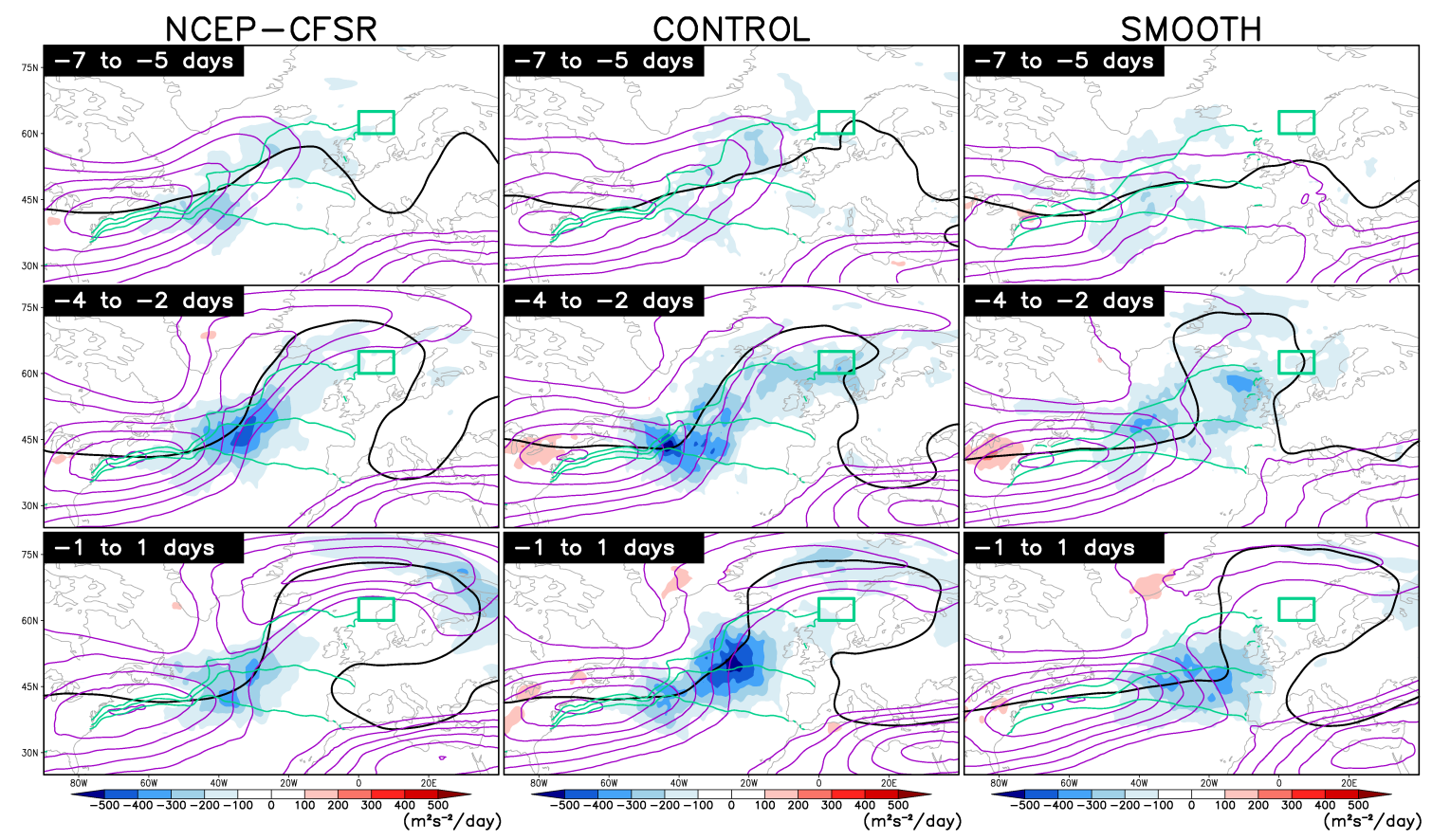

Figure 12. Evolution of the composite eddy kinetic energy conversion rate, $\mathbf{E} \cdot \mathbf{D}$, at $300 \mathrm{hPa}$ in the NCEP-CFSR, CONTROL and SMOOTH (shaded). Negative values show regions where the eddies are supplying energy to the low-frequency flow. The absolute value of the low-frequency wind composites are contoured in purple every $5 \mathrm{~m} / \mathrm{s}$ from $20 \mathrm{~m} / \mathrm{s}$. The thick black contours are PV composites at $300 \mathrm{hPa}$ for $1.75 \mathrm{PVU}$ in NCEP-CFSR and 2.25 in CONTROL and SMOOTH. Wintertime SST contours are drawn in green for $8^{\circ} \mathrm{C}, 12^{\circ} \mathrm{C}$ and $16^{\circ} \mathrm{C}$. The thick green box indicates the region used to produce the low-pass filtered geopotential height index. 


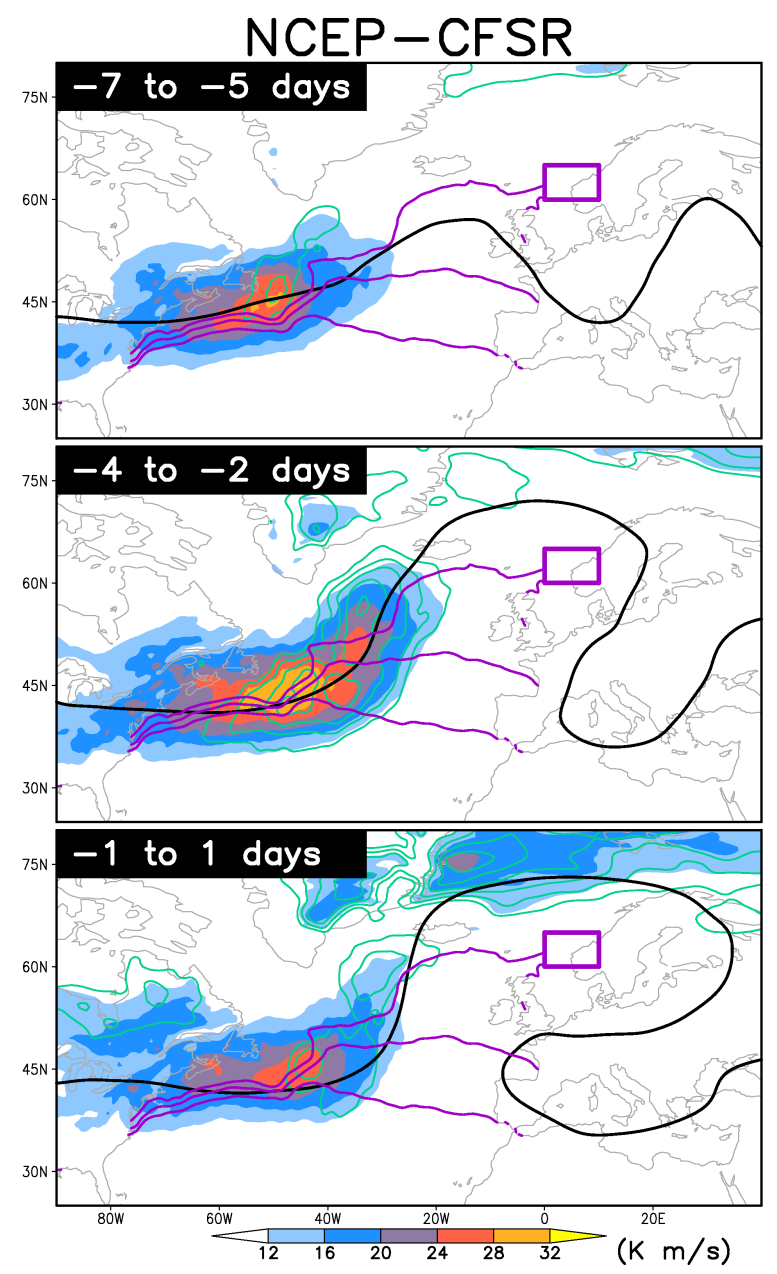

Figure 13. Evolution of the meridional eddy heat transport at $850 \mathrm{hPa}$, shaded, in the NCEPCFSR. Positive anomalies, relative to the climatology, are indicated in green contours, starting at $4 \mathrm{~K} \mathrm{~m} / \mathrm{s}$ with an interval of $2 \mathrm{~K} \mathrm{~m} / \mathrm{s}$. The thick black contour indicates where the composite PV at $300 \mathrm{hPa}$ is equal to $1.75 \mathrm{PVU}$. Wintertime SST contours are drawn in purple for $8^{\circ} \mathrm{C}, 12^{\circ} \mathrm{C}$ and $16^{\circ} \mathrm{C}$. The thick purple box indicates the region used to produce the low-pass filtered geopotential height index. 


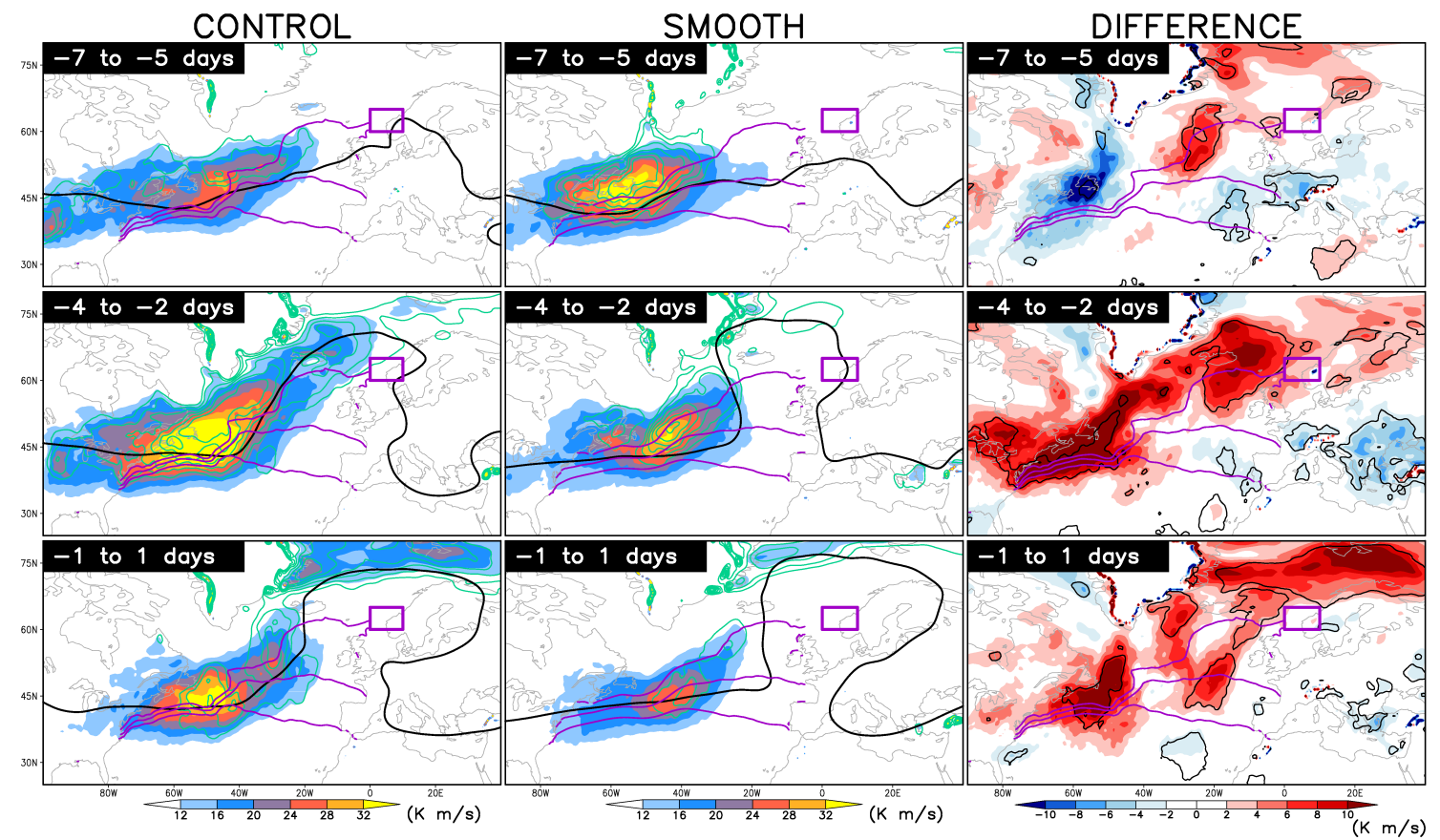

Figure 14. Evolution of the meridional eddy heat transport at $850 \mathrm{hPa}$, shaded, in the CONTROL and SMOOTH simulations. The DIFFERENCE, defined CONTROL minus $\mathrm{SMOOTH}$, is also shown. Positive anomalies, relative to the respective climatologies, are indicated in green contours, starting at $4 \mathrm{~K} \mathrm{~m} / \mathrm{s}$ with an interval of $2 \mathrm{~K} \mathrm{~m} / \mathrm{s}$. The thick black contour indicates where the composite $\mathrm{PV}$ at $300 \mathrm{hPa}$ is equal to $2.25 \mathrm{PVU}$. The thin black contours in the DIFFERENCE maps indicate regions where the difference between the composites is significant at the $10 \%$ significance level. Wintertime SST contours are drawn in purple for for $8^{\circ} \mathrm{C}, 12^{\circ} \mathrm{C}$ and $16^{\circ} \mathrm{C}$. The thick purple box indicates the region used to produce the low-pass filtered geopotential height index. 


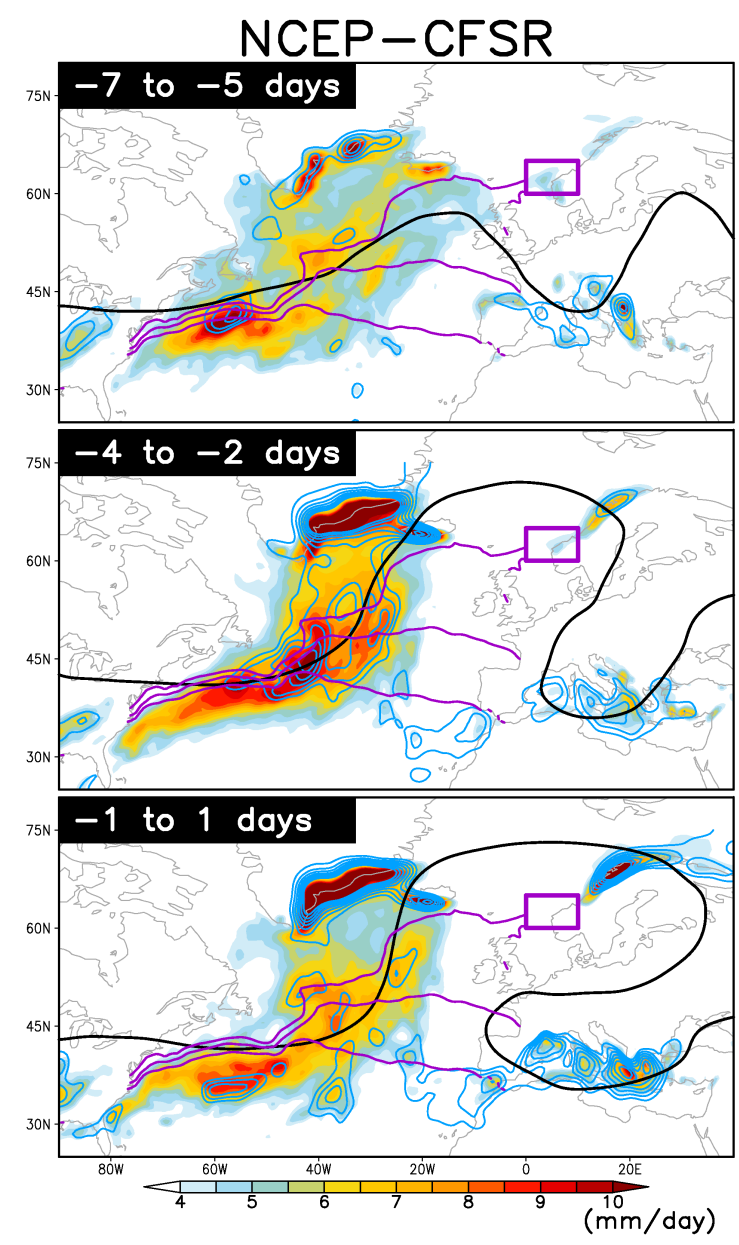

Figure 15. Composite evolution of the precipitation, shaded, during European blocking development in NCEP-CFSR. Blue contours indicate positive anomalies, relative to the climatology, starting at $1 \mathrm{~mm} /$ day with an interval of $0.5 \mathrm{~mm} /$ day. The thick black contour indicates where the composite $\mathrm{PV}$ at $300 \mathrm{hPa}$ is equal to $1.75 \mathrm{PVU}$. Wintertime SST contours are drawn in purple for for $8^{\circ} \mathrm{C}, 12^{\circ} \mathrm{C}$ and $16^{\circ} \mathrm{C}$. The thick purple box indicates the region used to produce the low-pass filtered geopotential height index. The precipitation anomaly contours have been lightly smoothed before plotting for clarity. 


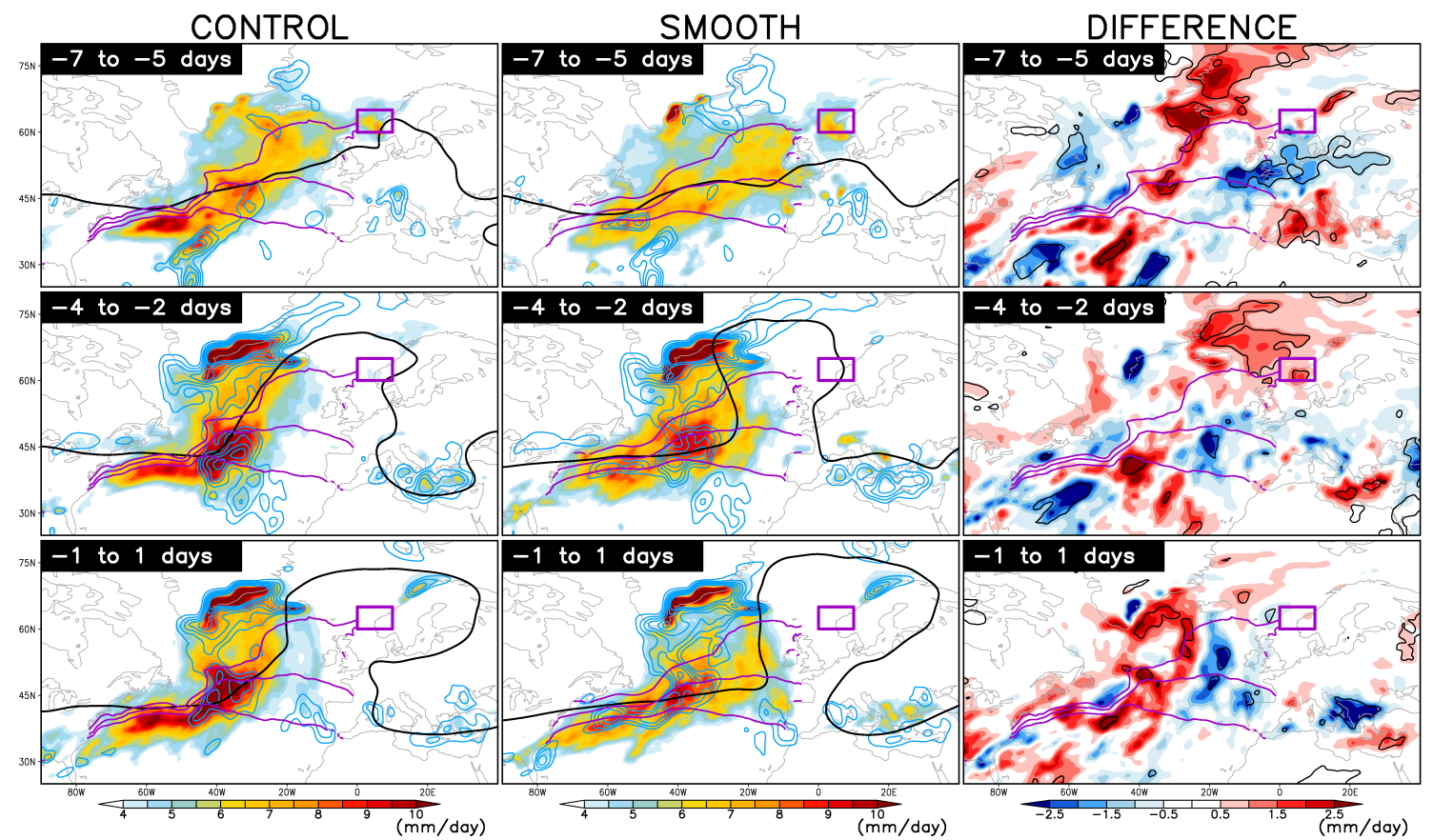

Figure 16. Composite evolution of the precipitation, shaded, during European blocking development in CONTROL and SMOOTH. The DIFFERENCE, defined CONTROL minus SMOOTH, is also shown. Blue contours indicate positive anomalies, relative to the respective climatologies, starting at $1 \mathrm{~mm} /$ day with an interval of $0.5 \mathrm{~mm} /$ day. The thick black contours indicates where the composite $\mathrm{PV}$ at $300 \mathrm{hPa}$ is equal to $2.25 \mathrm{PVU}$. The thin black contours in the DIFFERENCE maps indicate regions where the difference between the composites is significant at the $10 \%$ significance level. Wintertime SST contours are drawn in purple for for $8^{\circ} \mathrm{C}, 12^{\circ} \mathrm{C}$ and $16^{\circ} \mathrm{C}$. The thick purple box indicates the region used to produce the low-pass filtered geopotential height index. The precipitation anomaly contours have been lightly smoothed before plotting for clarity. 


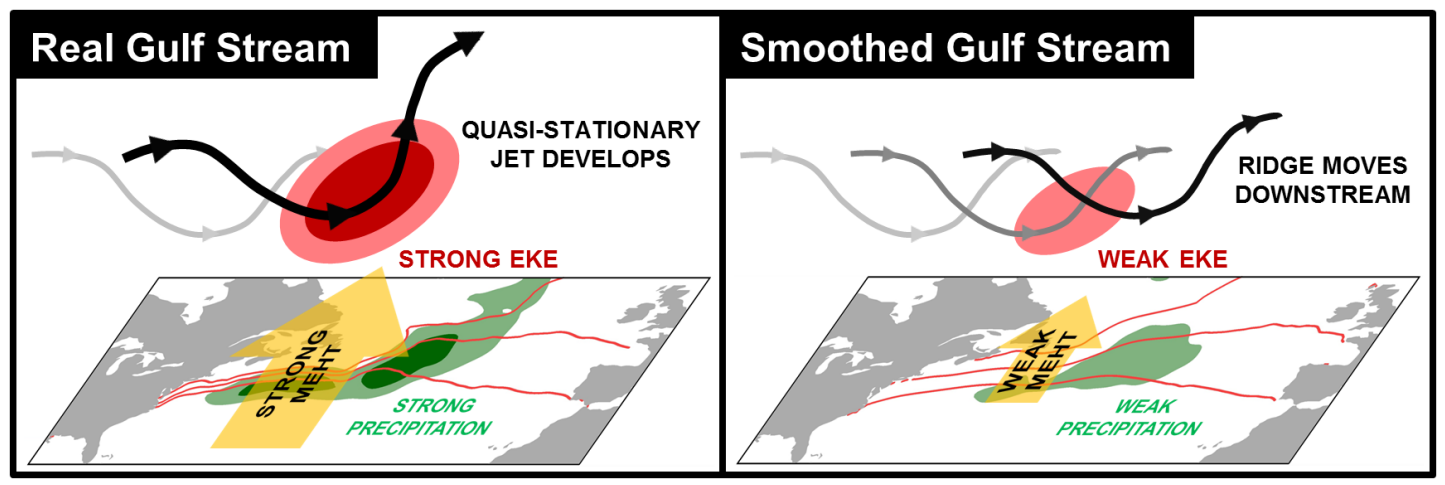

Figure 17. Schematic summarising the common features prior to European blocking highs with observed Gulf Stream SST (left), as in both NCEP-CFSR and CONTROL, and with smoothed Gulf Stream SST (right), as in SMOOTH simulation. The bold yellow arrows indicate the meridional eddy heat transport (MEHT) in the lower-troposphere. 
(a) European blocking (NCEP-CFSR)

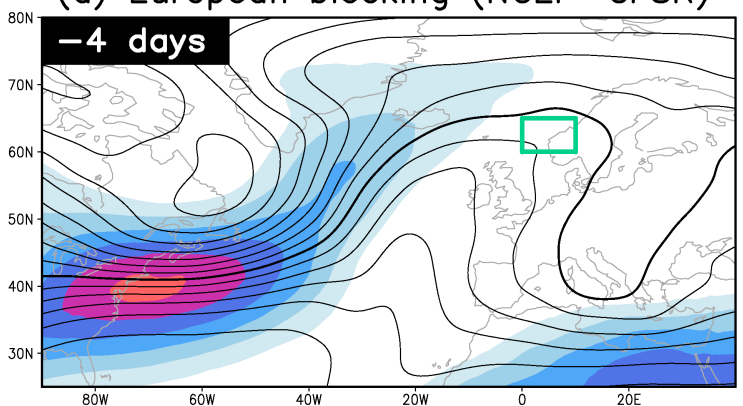

(b) Pacific blocking (NCEP-CFSR)

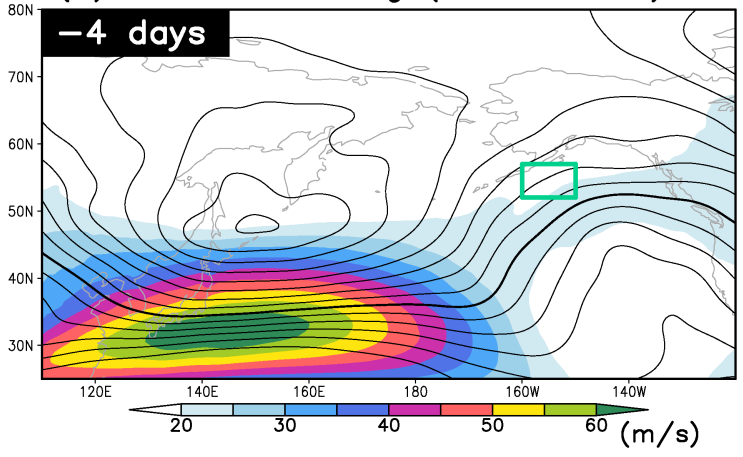

Figure 18. Absolute value of the composite velocity (shading) and PV at $300 \mathrm{hPa}$ (black contours from 0.5 PVU with an interval of 0.25 PVU, emboldened for 1.75 PVU) for the 8-day low-pass composite field at -4 days for the European blocking (top) and the eastern North Pacific blocking. These composites consist of the top 50 blocking events calculated only using the 8-day low-pass filtered $Z(500 \mathrm{hPa})$ indices (over the regions indicated by the green boxes), more closely following the method used in Nakamura et al. (1997). 